\title{
Interaction of dissolution, sorption and biodegradation on transport of BTEX in a saturated groundwater system: Numerical modeling and spatial moment analysis
}

\author{
Renu Valsala and Suresh Kumar Govindarajan* \\ Department of Ocean Engineering, Indian Institute of Technology-Madras, Chennai 600 036, India. \\ *Corresponding author.e-mail: gskumar@iitm.ac.in
}

MS received 3 January 2017; revised 8 July 2017; accepted 30 September 2017; published online 22 May 2018

Interaction of various physical, chemical and biological transport processes plays an important role in deciding the fate and migration of contaminants in groundwater systems. In this study, a numerical investigation on the interaction of various transport processes of BTEX in a saturated groundwater system is carried out. In addition, the multi-component dissolution from a residual BTEX source under unsteady flow conditions is incorporated in the modeling framework. The model considers Benzene, Toluene, Ethyl Benzene and Xylene dissolving from the residual BTEX source zone to undergo sorption and aerobic biodegradation within the groundwater aquifer. Spatial concentration profiles of dissolved BTEX components under the interaction of various sorption and biodegradation conditions have been studied. Subsequently, a spatial moment analysis is carried out to analyze the effect of interaction of various transport processes on the total dissolved mass and the mobility of dissolved BTEX components. Results from the present numerical study suggest that the interaction of dissolution, sorption and biodegradation significantly influence the spatial distribution of dissolved BTEX components within the saturated groundwater system. Mobility of dissolved BTEX components is also found to be affected by the interaction of these transport processes.

Keywords. Numerical modeling; spatial moment analysis; dissolution; non-linear sorption; sorption kinetics; biodegradation.

\section{List of notations}

$\propto_{L}^{m} \quad$ Longitudinal dispersivity of component $m[\mathrm{~L}]$

$b \quad$ Langmuir sorption constant $\left[\mathrm{L}^{3} \mathrm{M}^{-1}\right]$

$h \quad$ Pressure head $\left[\mathrm{ML}^{-1} \mathrm{~T}^{-2}\right]$

$C \quad$ volume concentration of solute $\left[\mathrm{ML}^{-3}\right]$

$C_{0}^{m} \quad$ Pure aqueous phase solubility of component $m\left[\mathrm{ML}^{-3}\right]$

$C_{s}^{m} \quad$ Effective solubility of component $D(t)$
$C_{w}^{m} \quad$ Aqueous concentration of component $m$ $\left[\mathrm{ML}^{-3}\right]$

$d_{50} \quad$ Mean grain diameter of aquifer material $\mathrm{mm}[\mathrm{L}]$

$D_{o} \quad$ Dispersion coefficient of dissolved oxygen $\left[\mathrm{L}^{2} \mathrm{~T}\right]$

$D^{m} \quad$ Diffusion coefficient of component $m$ $\left[\mathrm{L}^{2} \mathrm{~T}^{-1}\right]$

$D_{L}^{m} \quad$ Longitudinal dispersion coefficient of component $m\left[\mathrm{~L}^{2} \mathrm{~T}^{-1}\right]$

Effective diffusion coefficient at time $t$ $\left[\mathrm{L}^{2} \mathrm{~T}^{-1}\right]$ 
$f^{m} \quad$ Volumetric fraction of component $m$ $\left[\mathrm{L}^{2} \mathrm{~T}^{-1}\right]$

$K \quad$ Hydraulic conductivity of aquifer $\left[\mathrm{LT}^{-1}\right]$

$K_{d} \quad$ Linear distribution coefficient $\left[\mathrm{L}^{3} \mathrm{M}^{-1}\right]$

$K_{\text {decay }} \quad$ Biodegradation decay constant $\left[\mathrm{T}^{-1}\right]$

$K_{f} \quad$ Freundlich Sorpton coefficient $\left[\mathrm{L}^{3} \mathrm{M}^{-1}\right]$

$K_{o} \quad$ Half saturation constant of dissolved oxygen $\left[\mathrm{ML}^{-3}\right]$

$K_{s}^{m} \quad$ Half saturation constant of component $m\left[\mathrm{ML}^{-3}\right]$

$k_{r w} \quad$ Relative hydraulic conductivity [-]

$L \quad$ Length of the porous medium [L]

$M_{o} \quad$ Zeroth temporal moment $\left[\mathrm{ML}^{-3}\right]$

$M_{1} \quad$ First temporal moment $\left[\mathrm{ML}^{-3} \mathrm{~T}\right]$

$M_{2} \quad$ Second temporal moment $\left[\mathrm{ML}^{-3} \mathrm{~T}^{2}\right]$

$M^{m} \quad$ Mass of component $\mathrm{m}$ in groundwater system $[\mathrm{M}]$

$N \quad$ number of LNAPL components [-]

$n \quad$ Freundlich sorption intensity [-]

$\xi \quad$ Sorption mass transfer rate $\left[\mathrm{T}^{-1}\right]$

$q \quad$ Darcy flux $\left[\mathrm{LT}^{-1}\right]$

$Q_{\max } \quad$ Maximum Langmuir sorption capacity $\left[\mathrm{MM}^{-1}\right]$

$R \quad$ Retardation factor of aquifer [-]

$R_{f}^{m} \quad$ Retardation factor of component $m[-]$

$\rho_{b} \quad$ Bulk density of aquifer material $\left[\mathrm{ML}^{-3}\right]$

$\rho_{n} \quad$ Density of LNAPL $\left[\mathrm{ML}^{-3}\right]$

$\rho_{m} \quad$ Density of component $\mathrm{m}\left[\mathrm{ML}^{-3}\right]$

$S \quad$ Sorbed concentration $\left[\mathrm{MM}^{-1}\right]$

$S^{m} \quad$ Sorbed concentration of component $m$ $\left[\mathrm{MM}^{-1}\right]$

$S^{h} \quad$ Sherwood number [-]

$S_{n} \quad$ LNAPL saturation [-]

$S_{n 0} \quad$ Initial LNAPL saturation [-]

$S_{r w} \quad$ Residual LNAPL saturation [-

$S_{S} \quad$ Specific storage of aquifer $\left[\mathrm{L}^{-1}\right]$

$S_{w} \quad$ Water saturation [-]

$\lambda_{\text {diss }}^{m} \quad$ Lumped dissolution mass transfer coefficient of component $m\left[\mathrm{~T}^{-1}\right]$

$\lambda_{\text {bio }}^{m} \quad$ Biodegradation mass transfer coefficient of component $\mathrm{m}\left[\mathrm{T}^{-1}\right]$

$t \quad$ Time variable [T]

$\theta \quad$ Porosity $[-]$

$V(t) \quad$ Effective solute velocity at time $t\left[\mathrm{LT}^{-1}\right]$

$V_{\max }^{m} \quad$ Maximum substrate utilization rate of component $m\left[\mathrm{~T}^{-1}\right]$

$x \quad$ Space coordinate along the flow direction in the fracture plane [L]

$X \quad$ Biomass concentration $\left[\mathrm{ML}^{-3}\right]$

$X_{0} \quad$ Initial biomass concentration $\left[\mathrm{ML}^{-3}\right]$

$X_{1}(t) \quad$ Normalized first spatial moment [L]

$X_{11}(t) \quad$ Normalized second spatial moment $\left[\mathrm{L}^{2}\right]$
$X_{n}^{m} \quad$ Mole fraction of component $m$ in NAPL $[-]$

$y_{c}^{m} \quad$ Yield coefficient of component $m[-]$

$y_{o}$

Yield coefficient of dissolved oxygen [-]

\section{Introduction}

Release of petroleum hydrocarbons in the sub-surface poses serious threat to the soil and groundwater. Spill of petroleum hydrocarbons may lead to significant deterioration in groundwater quality due to the presence of highly toxic constituents like Benzene, Toluene, Ethyl Benzene and Xylene (BTEX). BTEX possess the highest mobility and solubility among petroleum hydrocarbons (Derrick et al. 2005). Moreover, the innate partitioning ability of BTEX will help its components to reach various compartments of the environment. Hence, it is very essential to investigate the fate and transport of BTEX to reduce the adverse effects of petroleum spill. Highly heterogeneous nature of the subsurface and association of many spatially and temporally varying physical, chemical and biological transport processes may make the monitoring of BTEX highly complex.

Numerous studies were conducted in the past few decades to investigate the migration of spilled BTEX in the subsurface environment (Powers et al. 1994; Lu et al. 1999; Prommer et al. 1999; Essaid et al. 2003; Atteia and Guillot 2007). BTEX are generally categorized under Light Non-Aqueous Phase Liquids (LNAPL) group of contaminants due to their immiscible nature and lighter density. Depending on the composition and environmental conditions of the aquifer, the free moving LNAPL phase of BTEX may get partitioned to: (i) residual phase (isolated portion of LNAPL); (ii) sorbed phase; and (iii) dissolved phase. In addition, the, microorganisms present in the subsurface environment may biodegrade the BTEX to inorganic substances. Figure 1 provides the detailed representation of various LNAPL transport processes in a saturated subsurface system.

Dissolution mass transfer from the residual phase LNAPL is a very complex process and is controlled by many factors such as saturation and distribution of LNAPL, heterogeneity and geochemical properties of aquifer, and fluid flow (Saba and Illangasekare 2000; Vasudevan et al. 2014). Earlier studies have used the local equilibrium assumption for modeling dissolution and 


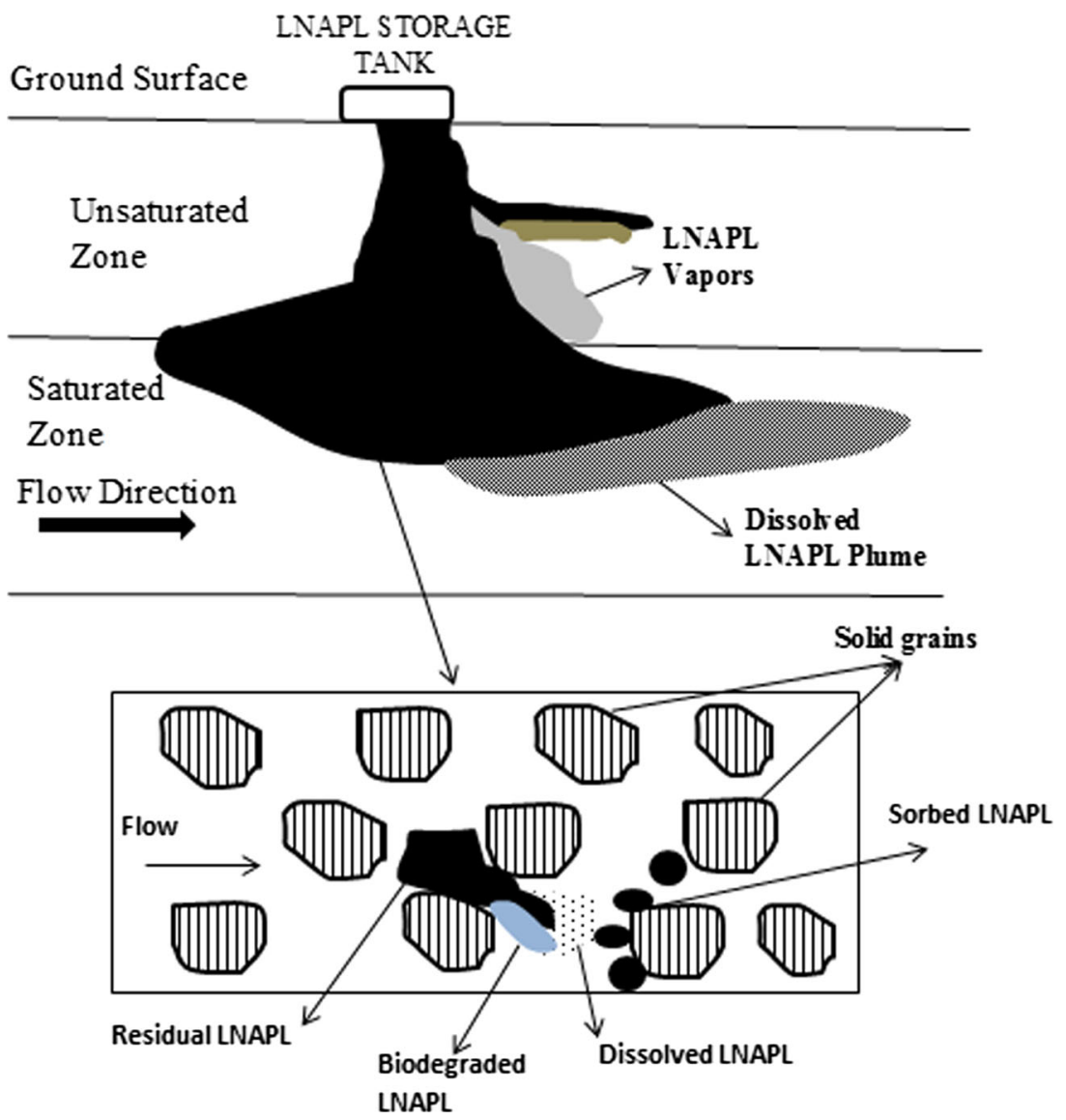

Figure 1. Schematic representation of transport processes of petroleum hydrocarbons in a groundwater system.

considered the rate of dissolution as its solubility limit. However, later studies have shown that the local equilibrium assumption is valid only during the early stages of the dissolution process (Imhoff et al. 1994; Powers et al. 1994; Javandel 1996; Hamed et al. 2000; Schaerlaekens et al. 2000; Nambi and Powers 2003). Moreover, during the later stages, dissolution mass transfer is affected by NAPL-water interfacial area and groundwater flow velocity. Further, the interaction of sorption and biodegradation processes is also found to affect the transport of dissolved LNAPLs. Research investigations carried out in the past indicated the significance of considering the influence of coupled transport processes on migration and phase partitioning of NAPL within the saturated subsurface system (Prommer et al. 2000; Clement et al. 2004).

Dissolution mass transfer of a component, when present in a multi-component NAPL mixture is further complex due to the variation of its effective solubility with NAPL composition (Borden and Piwoni 1992; Frind et al. 1999; Prommer et al. 1999; Vasudevan et al. 2012, 2014). Frind et al. (1999) conducted a field experiment using a borden emplaced multi-component DNAPL source to investigate the dissolution mass transfer of DNAPL components and suggested that the dissolution from a homogeneous borden emplaced source is nearly equilibrium controlled. Prommer et al. (2000) formulated a 1-D numerical model based on operator splitting techniques to model transport of BTEX and inorganic solutes by considering advection, dispersion and biodegradation. Rivett and Allen-King (2003) conducted field studies using an emplaced DNAPL source to investigate the effect of solute and co-solute concentrations on sorption and retardation and they have found that the concentration of solute and co-solute affects non-linear sorption and solute transport properties significantly. Clement et al. (2004) studied the transport of chlorinated solvents in a biologically reactive medium by conceptualizing dissolution process as mass-transfer limited reaction, sorption as a rate-limited process and biodegradation as a kinetic-limited process. Ojuri and Ola (2010) conducted laboratory experiments in a saturated sand tank to investigate transport and natural attenuation of BTEX compounds. A 3-D finite 
difference numerical model was developed to model advection, dispersion and reaction of BTEX compounds. Geochemical parameters observed in the tank indicated the presence of biodegradation.

Despite many studies being conducted in the past to investigate the transport of aqueous concentration of BTEX compounds, very few studies investigated the effect of interaction of coupled reactions on the spatial distribution of BTEX concentration in a saturated groundwater aquifer. Moreover, no study has been done to investigate the influence of natural reactions on the transport characteristics of dissolved BTEX components. Research studies conducted in the past indicated the relevance of carrying out moment analysis along with numerical simulation to quantify transport parameters of solutes (Sekhar and Suresh Kumar 2005; Renu and Suresh Kumar 2012, 2014). Mobility and dispersivity of solute plumes cannot be deduced directly from the spatial distribution of solute concentration within the porous system. Moreover, in most of the cases, spatial concentration data obtained from the field or experimental studies may be highly sparse and therefore classical method of parameter estimation methods cannot be used to accurately predict transport parameters of a solute plume (Govindarajau and Das 2007). In such cases, method of spatial moments can be used to estimate the transport characteristics of a solute plume more accurately since spatial moments are computed using average statistical properties of solute distribution at each location. Thus the spatial moment analysis can be used as a powerful tool to accurately estimate transport parameters of solute plume such as solute velocity, dispersion coefficient, dispersivity, etc.

In the present study, an attempt has been made to investigate the influence of interaction of multi-component dissolution, sorption and aerobic biodegradation on spatial and temporal distribution of dissolved Benzene, Toluene, Ethyl Benzene and Xylene concentration in a saturated groundwater aquifer. Subsequently, a lower order spatial moment analysis has been carried out to quantify the transport parameters of BTEX compounds under the interaction of various transport processes. Temporal variation of total dissolved mass and effective mobility of BTEX components is obtained by computing the zeroth and first spatial moment of concentration breakthrough profiles. The proposed numerical analysis can be used to predict the spatial and temporal concentration of dissolved BTEX components in saturated groundwater system.

\section{Physical system and model development}

The present modeling study is carried out in a saturated homogeneous groundwater aquifer of length $12.5 \mathrm{~m}$. A residual BTEX source zone of length $0.5 \mathrm{~m}$ is considered to be situated at a distance of $0.5 \mathrm{~m}$ from the left boundary of the aquifer. The residual BTEX source zone is considered to be immobile for the flow conditions existing in the reservoir. Physical properties of the aquifer considered for the numerical simulation is provided in table 1 . Input parameters for the BTEX source zone is provided in table 2. A one-dimensional numerical model based on finite difference approach is developed to model coupled flow and transport of dissolved BTEX in a saturated groundwater aquifer.

\subsection{Modeling of groundwater flow}

Groundwater flow is considered to occur in the direction parallel to the aquifer length. Ground water flow equation in a saturated aquifer is governed by the continuity equation and can be expressed as provided in equation (1) (Frind et al. 1999)

$$
-K k_{r w} \frac{\partial^{2} h}{\partial x^{2}}+S_{w} S_{s} \frac{\partial h}{\partial t}+\theta \frac{\partial S_{w}}{\partial t}=0
$$

In equation (1), $K$ represents the hydraulic conductivity $\left(\mathrm{LT}^{-1}\right), S_{s}$ represents the specific storage $\left(\mathrm{L}^{-1}\right), \theta$ represents the porosity, $h$ represents the hydraulic head in $m(\mathrm{~L}), S_{w}$ represents the water saturation $(-), t$ represents the time $(T)$ and $k_{r w}$ represents the relative permeability of water

Table 1. Physical properties of aquifer considered for analysis (Frind et al. 1999).

\begin{tabular}{lc}
\hline Property & Value \\
\hline Hydraulic conductivity, $K(\mathrm{~m} / \mathrm{s})$ & $0.5 \times 10^{-4}$ \\
Porosity, $\theta$ & 0.33 \\
Gradient of aquifer & 0.01 \\
Median grain size, $d_{50}(\mathrm{~mm})$ & 0.15 \\
Initial DNAPL saturation, $S_{n}$ & 0.05 \\
Residual water saturation, $S_{r w}$ & 0.07 \\
Specific storage, $S_{s}\left(\mathrm{~m}^{-1}\right)$ & 0.001 \\
Total length of aquifer, $m$ & 12.5 \\
Bulk density of aquifer material $(\mathrm{kg} / \mathrm{L})$ & 1.60 \\
\hline
\end{tabular}


Table 2. Source LNAPL properties used for simulating the dissolution mass transfer.

\begin{tabular}{|c|c|c|c|c|c|}
\hline Property & Benzene & Toluene & $\begin{array}{l}\text { Ethyl } \\
\text { Benzene }\end{array}$ & Xylene & Total \\
\hline Initial mass, $\mathrm{kg}$ & 5 & 5 & 5 & 5 & 20 \\
\hline Initial volume, $\mathrm{L}$ & 5.71 & 5.75 & 5.75 & 5.75 & 22.96 \\
\hline Density, $\mathrm{kg} \mathrm{L}^{-1}$ & 0.876 & 0.87 & 0.87 & 0.87 & \\
\hline Molecular weight, $\mathrm{kg} \mathrm{mol}^{-1}$ & 0.078 & 0.092 & 0.106 & 0.106 & \\
\hline Moles & 64.1 & 54.35 & 47.17 & 47.17 & 212.79 \\
\hline Initial mole fraction, $X^{m}$ & 0.30 & 0.26 & 0.22 & 0.22 & \\
\hline Pure phase solubility, $C_{0}, \mathrm{mg} \mathrm{L}^{-1}$ & 1780 & 515 & 152 & 198 & \\
\hline Initial effective solubility, $\mathrm{mg} \mathrm{L}^{-1}$ & 534 & 133.9 & 33.44 & 43.56 & \\
\hline Molecular diffusion coefficient & $7.78 \times 10^{-7}$ & $6.05 \times 10^{-7}$ & $5.18 \times 10^{-7}$ & $5.18 \times 10^{-7}$ & \\
\hline
\end{tabular}

$(-) . k_{r w}$ can be computed as a function of $S_{w}$ (Corey 1986) as given in equation (2)

$$
k_{r w}=\left[\frac{S_{w}-S_{r w}}{1-S_{r w}}\right]^{4} .
$$

In equation (2), $S_{r w}$ represents the residual water saturation. Saturation of LNAPL and water are related as given in equation (3)

$$
S_{w}+S_{n}=1 \text {. }
$$

Groundwater flow equation is solved based on the following initial and boundary conditions. Initial heads at all nodes are computed based on the initial hydraulic gradient. Left and right boundary of aquifer is maintained at constant heads for all time levels.

$$
h(x=0, t)=h_{0} ; \quad h(x=L, t)=h_{1} .
$$

Groundwater flow equation is solved to obtain the hydraulic head distribution at all nodes for a particular time level. Having obtained the hydraulic head distribution, Darcy velocity is computed as provided in equation (5).

$$
q=-K k_{r w} \frac{\partial h}{\partial x}
$$

\subsection{Modeling of coupled multi-component dissolution, sorption and biodegradation}

The present model considers Benzene, Toluene, Ethyl Benzene and Xylene dissolving from the residual BTEX source zone to undergo sorption and aerobic biodegradation, in addition to advection and dispersion. Sorption of BTEX components on the aquifer particles may be either equilibrium controlled or rate-limited depending upon the contact time, saturation, groundwater flow velocity and on physiochemical properties of the aquifer material (Site 2001). Hence, the transport equation adopted for modeling transport of dissolved BTEX components is formulated to incorporate both equilibrium and kinetic sorption terms. The transport equation of component, $m$ in the LNAPL mixture is expressed as in equation (6) (Molson et al. 2002).

$$
\begin{aligned}
& R_{f}^{m} \theta S_{w} \frac{\partial C_{w}^{m}}{\partial t}+\rho_{b} \frac{\partial S^{m}}{\partial t}+q \frac{\partial C_{w}^{m}}{\partial x} \\
& \quad-S_{w} \theta D_{L}^{m} \frac{\partial^{2} C_{w}^{m}}{\partial x^{2}}-\theta S_{w} \lambda_{\text {diss }}^{m}\left(C_{s}^{m}-C_{w}^{m}\right) \\
& \quad-\theta S_{w} \lambda_{\text {bio }}^{m} C_{w}^{m}=0 .
\end{aligned}
$$

In equation (6), $C_{w}^{m}$ represents the aqueous concentration of component $m, C_{s}^{m}$ represents the effective solubility limit of component $m, S^{m}$ represents the sorbed concentration of component $m$, $R_{f}^{m}$ represents the retardation factor of component $m, \theta$ represents the porosity, $\rho$ represents the mass density, $\lambda_{\text {diss }}^{m}$ represents the dissolution mass transfer coefficient $\left(\mathrm{T}^{-1}\right)$ of component $m$ and $\lambda_{\text {bio }}^{m}$ represents the biodegradation transfer coefficient of component $m\left(\mathrm{~T}^{-1}\right)$ and $D_{L}^{m}$ represents the hydrodynamic dispersion coefficient of component $m\left(\mathrm{~L}^{2} \mathrm{~T}^{-1}\right)$.

In equation (6), first term on the LHS represents the transient term, second term represents the sorption of dissolved BTEX on aquifer material which is kinetic controlled, third term represents the advective transport, fourth term represents the dispersive transport, fifth term represents the dissolution from the residual source zone and sixth term represents the biodegradation of dissolved BTEX components, $R_{f}^{m}$ (retardation factor of component $m$ ) is incorporated to take into account the retardation caused due to the equilibrium controlled sorption of dissolved BTEX components on aquifer material. 
The dissolution mass transfer coefficient $\left(\lambda_{\text {diss }}^{m}\right)$ in the dissolution term is time dependent due to the variation in NAPL composition and interfacial area. In order to account for varying NAPL composition, Frind et al. (1999) formulated an expression for the mass transfer limitation from a residual NAPL source by incorporating the volumetric fraction

$$
\lambda_{\mathrm{diss}}^{m}=\frac{S_{h} D^{m}}{\left(d_{50}\right)^{2}}\left(\frac{f^{m} S_{n}}{S_{0}}\right)^{\beta^{m}} .
$$

In equation (7), $S_{h}$ represents the Sherwood number $(-), D^{m}$ represents the diffusion coefficient of component $m\left(\mathrm{~L}^{2} \mathrm{~T}^{-1}\right), f^{m}$ represent the volumetric fraction of component $m(-), d_{50}$ represents the mean grain diameter in $\mathrm{mm}(\mathrm{L}), S_{n}$ represents the LNAPL saturation $(-), S_{0}$ represents the initial LNAPL saturation $(-), \beta^{m}$ represents the exponent of component $m(-)$.

The effective solubility of component $m\left(C_{s}^{m}\right)$ in the dissolution term can be computed according to the Raoult's law, in an ideal solution of multicomponent mixture. The effective solubility of a component can be computed as given in equation (8)

$$
C_{s}^{m}=C_{0}^{m} X_{n}^{m}
$$

In equation (8), $C_{0}^{m}$ represents the aqueous solubility of the pure component $m\left(\mathrm{ML}^{-3}\right), X_{n}^{m}$ represents the mole fraction of component $m(-)$.

In case of low groundwater flow velocity, contact time between residually trapped BTEX and aquifer will be more and in such cases, equilibrium sorption isotherms may better predict the sorption condition existing in the aquifer. In equation (6), the effect of equilibrium sorption is incorporated by an instantaneous retardation factor. Based on the interaction of flow regime, the distribution of BTEX between the liquid phase and sorbed phase may vary and it may be described by various sorption isotherms. The present modeling study analyzed three various sorption isotherms; Linear, Freundlich and Langmuir sorption isotherms. Expressions governing the instantaneous retardation factor and sorbed concentration is provided in the Appendix. In case of high groundwater flow velocity, partitioning of dissolved contaminant between solid and liquid phases is rate-limited and the simulated concentration is found to have intermediate stages of retardation (Clement et al. 2004). The sorption kinetics can be described by a first order mass transfer term containing a concentration gradient and can be expressed as given in equation (9)

$$
\frac{\rho}{\theta} \frac{\partial S}{\partial t}=\xi\left(C_{w}-\frac{S}{K_{d}}\right)
$$

In equation (9), $S$ represents the sorbed concentration $\left(\mathrm{ML}^{-3}\right), K_{d}$ represents the partition coefficient $\left(\mathrm{ML}^{-3}\right), \xi$ represents the mass transfer rate parameter $\left(\mathrm{T}^{-1}\right)$.

The biodegradation term in equation $(6),\left(\lambda_{\text {bio }}^{m}\right)$ is modeled by a double-Monod kinetic model. The present numerical analysis has incorporated the aerobic biodegradation of BTEX compounds with dissolved oxygen. The biodegradation rate is limited by the concentration of BTEX components (electron donors in the biodegradation reaction) as well as by the concentration of dissolved oxygen (electron acceptor in the biodegradation reaction). The biodegradation rate is also controlled by the concentration of aerobic microorganisms. According to multiplicative Monod kinetic model, biodegradation mass transfer rate for component $\mathrm{m}$ is computed as expressed in equation (10) (Prommer et al. 1999; Molson et al. 2002).

$$
\lambda_{\text {bio }}^{m}=V_{\max }^{m} X \frac{1}{C_{w}^{m}+K_{s}^{m}} \frac{C_{o}}{C_{o}+K_{o}} .
$$

In equation (10), $V_{\max }^{m}$ represents the maximum substrate utilization rate for component $m, X$ represents the biomass concentration $(\mathrm{mg} / \mathrm{l}), K_{s}^{m}$ represents the half saturation constant for component $m(\mathrm{mg} / \mathrm{l}), C_{o}$ represents the concentration of dissolved oxygen $(\mathrm{mg} / \mathrm{l})$ and $K_{o}$ represents the half saturation constant of dissolved oxygen (mg/l).

Since the biodegradation rate of BTEX components is dependent on the concentration of dissolved oxygen and microbes, the temporal change in dissolved oxygen and microbial concentration within the aquifer needs to be simulated. The dissolved oxygen transport within the aquifer is simulated by considering advection, dispersion and biodegradation. Sorption of dissolved oxygen on the aquifer solid particles is considered to be insignificant. The transport equation for dissolved oxygen is given as expressed in equation (11) (Molson et al. 2002) 


$$
\begin{aligned}
\frac{\partial C_{o}}{\partial t} & +q \frac{\partial C_{o}}{\partial x}-D_{o} \frac{\partial^{2} C_{o}}{\partial x^{2}} \\
& +\frac{C_{o}}{K_{o}+C_{o}} X \sum_{m=1}^{N} V_{\max }^{m} \frac{y_{c}^{m}}{y_{c}^{o}} \frac{C_{w}^{m}}{K_{s}^{m}+C_{w}^{m}} \\
= & 0 .
\end{aligned}
$$

In equation (11), $y_{c}^{m}$ represents the yield coefficient of component $m, y_{o}^{m}$ represents the yield coefficient of dissolved oxygen and $N$ represents the total number of components in the LNAPL mixture.

The microbial concentration within the aquifer is considered to be immobile for the flow conditions considered and the temporal change in microbial concentration due to biodegradation can be expressed as given in equation (12) (Molson et al. 2002)

$$
\begin{aligned}
\frac{\partial X}{\partial t}= & \frac{C_{o}}{K_{o}+C_{o}} X \sum_{m=1}^{N} V_{\max }^{m} y_{c}^{m} \frac{C_{w}^{m}}{K_{s}^{m}+C_{w}^{m}} \\
& -b\left(X-X_{0}\right) .
\end{aligned}
$$

In equation (12), $X_{0}$ is the initial biomass concentration $(\mathrm{mg} / \mathrm{l})$.

The spatial distribution of dissolved concentration of Benzene, Toluene, Ethyl Benzene and Xylene is obtained by solving equation (4). Having obtained the dissolved BTEX component concentration, mass of each BTEX component remaining in the residual source zone can be written as expressed in equation (13) (Frind et al. 1999)

$$
\partial M^{m} / \partial t+\theta S_{w} \lambda^{m}\left(C_{s}^{m}-C_{w}^{m}\right)=0 .
$$

After obtaining the mass of all BTEX components using equation (13), LNAPL density can be computed as provided in equation (14)

$$
\rho_{n}=\sum_{m} M^{m} \rho^{m} / \sum_{m} M^{m} .
$$

In equation (14), $\rho_{n}$ represents the density of LNAPL mixture $\left(\mathrm{ML}^{-3}\right), M^{m}$ represents the mass of component $m(\mathrm{M})$ and $\rho^{m}$ represents the density of component $m\left(\mathrm{ML}^{-3}\right)$.

Total mass depleted from the NAPL phase through dissolution is the sum of the individual component masses $M^{m}$ lost in the same time interval and the mass balance equation for LNAPL mixture can be provided as given in equation (15) (Frind et al. 1999)

$$
\theta\left(\partial S_{n} \rho_{n} / \partial t\right)+\sum_{m}\left[\theta S_{w} \lambda^{m}\left(C_{s}^{m}-C_{w}^{m}\right)\right]=0 .
$$

All the four BTEX compounds are assumed to have a zero dissolved concentration at the left boundary for all time levels. No flow boundary condition is assumed at the right boundary for the transport equations of dissolved BTEX components. Dissolved BTEX concentration at all nodes is considered to be zero at time $t=0$. Initial sorbed concentration at all nodes is also assumed to be zero. For modeling biodegradation, a constant, continuous source of dissolved oxygen is considered at the inlet. At the left boundary concentration of dissolved oxygen has been considered as $5 \mathrm{mg} / \mathrm{l}$ for all time levels. At the right boundary, no flow boundary condition is considered to solve the transport equation for dissolved oxygen. Concentration of dissolved oxygen is considered to be zero at time $t=0$. A biomass concentration of $1 \mathrm{mg} / \mathrm{l}$ has been considered at all nodes when time $t=0$.

\section{Numerical method and spatial moment analysis}

In the present numerical model, groundwater aquifer is assumed to be fully saturated, homogeneous and isotropic and the groundwater flow is assumed to be horizontal and incompressible. Groundwater flow equation and transport equations for all components are solved in a 1-D framework using finite difference method. The ground water flow equation is discretised using the fully implicit finite difference cell centered scheme. The transport equation is solved using an operator splitting approach. The transport equation has been split into advection, dispersion, dissolution, sorption and biodegradation operators. The advection operator is discretised using upwind scheme and the dispersion operator is discretised using the Crank-Nicholson finite difference scheme. Reaction operators (dissolution, sorption and biodegradation) are solved using fourth order Runge-Kutta Scheme. Transport equation for dissolved oxygen is also solved using the operator-splitting approach. The transport equation for dissolved oxygen is split into advection, dispersion and biodegradation operator. Advection and dispersion operators are solved using the finite difference scheme and biodegradation operator is solved using the 


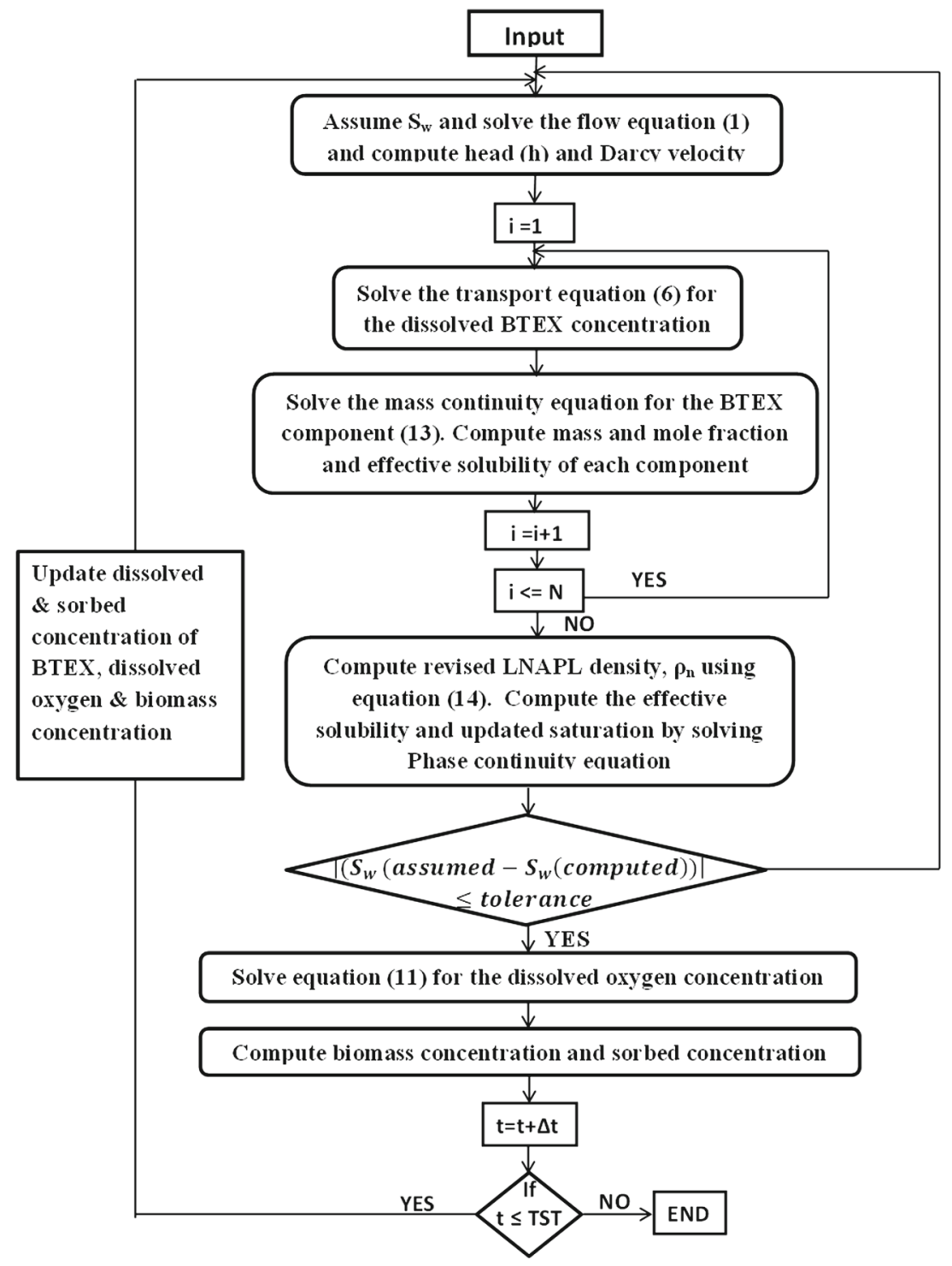

Figure 2. Algorithm for numerical modeling coupled fluid flow, dissolution, non-linear sorption and biodegradation of petroleum hydrocarbons.

fourth order Runge-Kutta method. A uniform grid size of $0.01 \mathrm{~m}$ is adopted for the spatial discretisation and a uniform time step of 0.01 day is adopted for the temporal discretisation. The algorithm adopted to solve couple flow and transport of BTEX in a saturated aquifer is provided in figure 2 .

Having obtained the aqueous concentration of all the three components along the entire spatial domain for all time levels, lower order spatial moments of concentration of all the components are computed as a function of time. Using a method of spatial moment, time dependent nature of transport characteristics (total dissolved mass and mobility) of the BTEX components can be studied. Spatial moments are obtained by integrating the solute concentration at all nodes over the entire spatial domain for a particular time interval.

The total aqueous concentration of solute within the porous medium can be computed by computing the zeroth moment $\left(M_{0}\right)$, the displacement of the center of mass of the solute is described by computing the first spatial moment $\left(M_{1}\right)$ (Goltz and Roberts 1987; Gelhar 1993; Ezzedine and Rubin 1997; Renu and Suresh Kumar 2012). Zeroth spatial moment $\left(M_{0}\right)$ and first spatial moment $\left(M_{1}\right)$ can be computed as expressed in equation (16) (Guven et al. 1984). The first spatial moment, normalized by the total aqueous mass of solute $\left(X_{1}(t)\right)$ provides the location of the center of mass of the aqueous concentration plume 


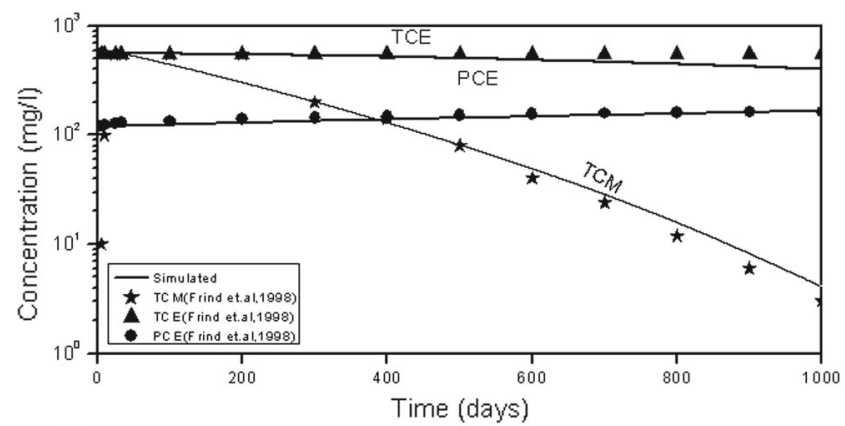

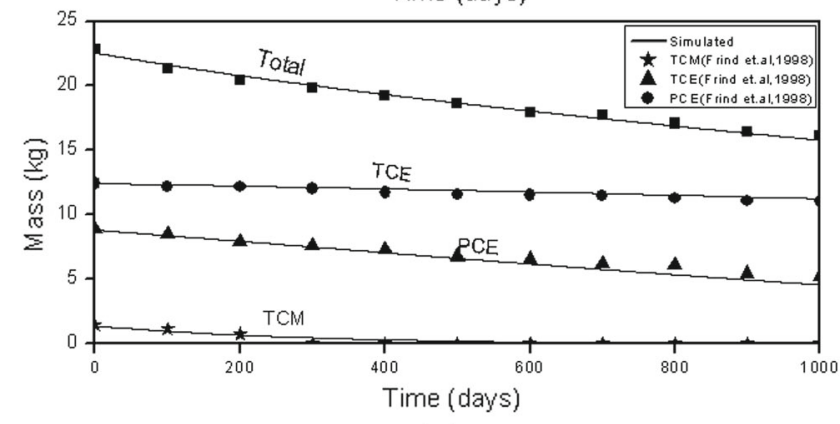

(a)

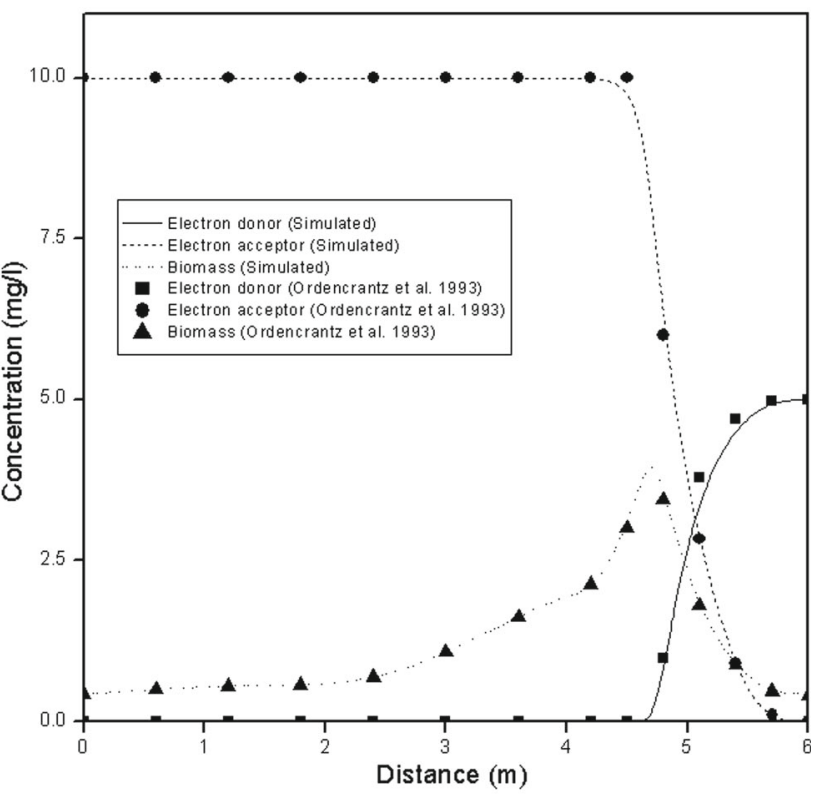

(b)

Figure 3. Validation of developed numerical model: (a) comparison of the multi-component dissolution data obtained using the developed numerical model with the existing solution provided in Frind et al. (1999). (b) Comparison of the biodegradation data obtained using the present model with the numerical solution provided in Ordencrantz et al. (1993).

$$
\begin{aligned}
& M_{0}=\int_{0}^{L} c(x) d x ; \quad M_{1}=\int_{0}^{L} x c(x, t) d x, \\
& X_{1}(t)=\frac{M_{1}}{M_{0}} .
\end{aligned}
$$

The velocity of the solute plume can be obtained from the rate of change of normalized first spatial moment with respect to time. Time dependent characteristics of transport parameters such as effective solute velocity can be obtained using the following expressions

$$
V(t)=\frac{d\left\{X_{1}(t)\right\}}{d t} .
$$

where $V(t)$ represents the velocity of solute at a time $(t)$.

\section{Verification of numerical model}

Verification of the developed numerical model is carried out by comparing its results with two existing solutions. The present numerical model is validated with the field and numerical results provided in Frind et al. (1999) to ensure that the numerical model is simulating the multi-component dissolution from the emplaced NAPL source precisely. Validation of the numerical model with
Ordencrantz et al. (1993) is carried out to check the ability of the numerical model to simulate the interaction between sorption and biodegradation accurately.

Figure 3(a) provides the comparison between the present numerical model and the results provided in Frind et al. (1999). Frind et al. (1999) conducted a field experiment using a borden emplaced DNAPL source to investigate the dissolution mass transfer from a residual DNAPL source zone. They also developed a 3-D finite element model to simulate the dissolution mass transfer. Figure 3(a.i) provides the temporal distribution of aqueous concentration of DNAPL compounds at a distance of $1 \mathrm{~m}$ from the source zone and figure 3(a.ii) provides the temporal distribution of mass of DNAPL components remaining in the source zone. It can be seen from figure 3(a) that the results of the present model match well with the results provided in Frind et al. (1999), thus validating the present model.

Figure 3(b) provides the comparison between the simulation results of the present model and the results provided in Ordencrantz et al. (1993). Ordencrantz et al. (1993) developed a numerical model using the operator splitting method to investigate the interaction between equilibrium sorption and biodegradation. Biodegradation is modeled using multiplicative Monod model by considering Acetate as electron donor and Nitrate as electron 
acceptor. Results obtained using present numerical model for simulation time of 75 days is compared with the results provided in Ordencrantz et al. (1993). It can be seen from figure 3(b) that concentration profiles of electron donor, acceptor and biomass obtained using the present numerical model match well with that provided in Ordencrantz et al. (1993), thus validating the present model.

\section{Results and discussions}

Simulations are carried out to investigate the dissolution mass transfer from a BTEX source zone under the influence of various coupled reactive transport processes. Spatial distribution of Benzene, Toluene, Ethyl Benzene and Xylene after a simulation period of 50 days is presented in the figures for all simulation cases. Lower order spatial moments (zeroth and normalized first spatial moment) of all four BTEX components are computed in all simulation cases. However, spatial moment variation of Benzene alone is presented in the figures for brevity.

\subsection{Influence of interaction of sorption and aerobic biodegradation}

Figure 4 illustrates the spatial distribution of dissolved concentration and the temporal distribution of transport characteristics of BTEX components under the following reaction conditions: (a) dissolution, (b) dissolution and linear sorption, and (c) dissolution, linear sorption and biodegradation. Figure 4(a) provides the spatial distribution of dissolved BTEX components after a total simulation period of 50 days. It can be seen from figure 4(a) that when biodegradation and sorption act along with dissolution, aqueous concentration of BTEX components is significantly reduced. It can be further noted from figure 4(a) that the sorption significantly affects the descending limbs and peaks of the concentration profile, whereas the ascending limbs of concentration profiles are not significantly influenced by sorption. This behavior indicates that sorption influences the dissolved concentration of BTEX components only after the source zone location (up to $1 \mathrm{~m}$ away from the left boundary). Till dissolved BTEX components reach the source zone, the retardation effect caused by sorption and biodegradation may be compensated by higher rate of dissolution mass transfer from the residual BTEX source zone. Further, it can be noted from figure 4(a) that the sorption mostly influences the dissolution of higher solubility components in the BTEX mixture (Benzene and Toluene). It can also be seen from figure 4(a) that the biodegradation affects the ascending limb and peak of aqueous concentration more due to the higher concentration of the electron accept or present near the left boundary. Biodegradation rate of dissolved BTEX components is limited by the availability of electron acceptor (dissolved oxygen) observed at locations with no dissolved oxygen concentration.

Figure 4(b) provides temporal variation of zeroth and normalized first spatial moment of Benzene for the same data shown in figure 4(a). First plot of figure 4(b) shows the temporal variation of zeroth spatial moment of dissolved Benzene concentration. Zeroth spatial moment provides a measure of the area under the concentration profiles and gives a measure of dissolved Benzene mass remaining within the system. It can be seen from figure 4(b.i) that sorption significantly reduces the dissolved mass of Benzene, whereas biodegradation does not cause much reduction in dissolved mass. It can also be noted from figure 4(b.i) that sorption and biodegradation significantly start affecting the aqueous mass of Benzene after a total simulation period of 10 days. Second plot of figure 4(b) provides temporal variation of normalized first spatial moment of Benzene. Effective velocity of Benzene can be deduced from slope of the profiles. A linear variation of the normalized first spatial moment indicates that Benzene possesses constant velocity (time independent velocity) under all three reaction conditions considered for analysis. Further it can be noted from figure 4(b) that sorption is causing significant retardation in mobility of Benzene, whereas the biodegradation does not offer any retardation to Benzene mobility. Overall, it can be concluded that sorption affects the dissolved BTEX concentration only during later stages, whereas the biodegradation influences dissolved BTEX transport during the early stages.

\subsection{Influence of equilibrium sorption isotherms on BTEX transport}

Figure 5(a) provides the spatial variation of dissolved concentration of Benzene, Toluene, Ethyl Benzene and Xylene for different equilibrium sorption isotherms. In order to compare the influence of different equilibrium sorption isotherms, 


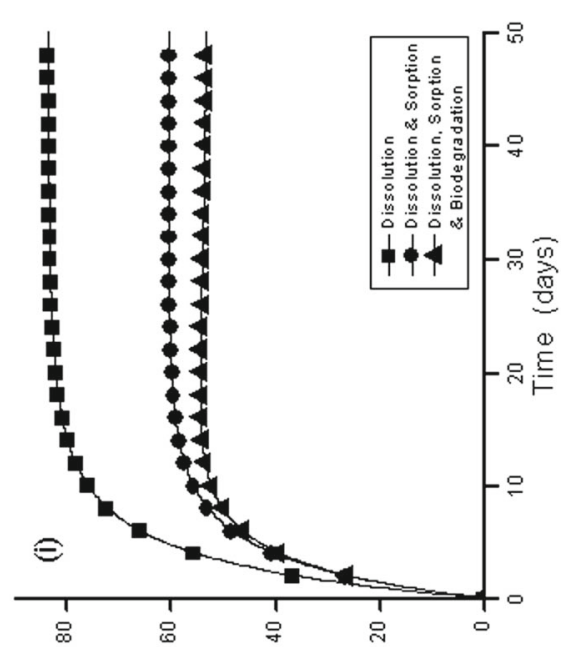

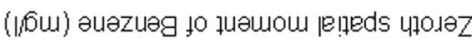

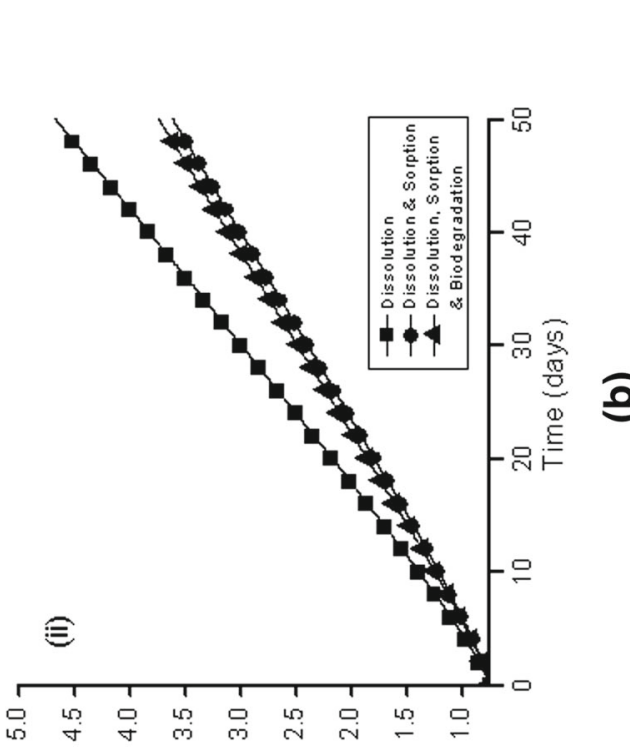

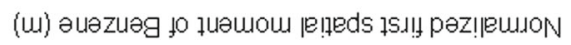

政
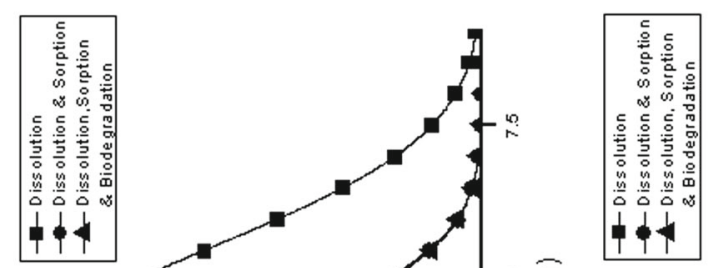

हี

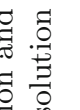



2
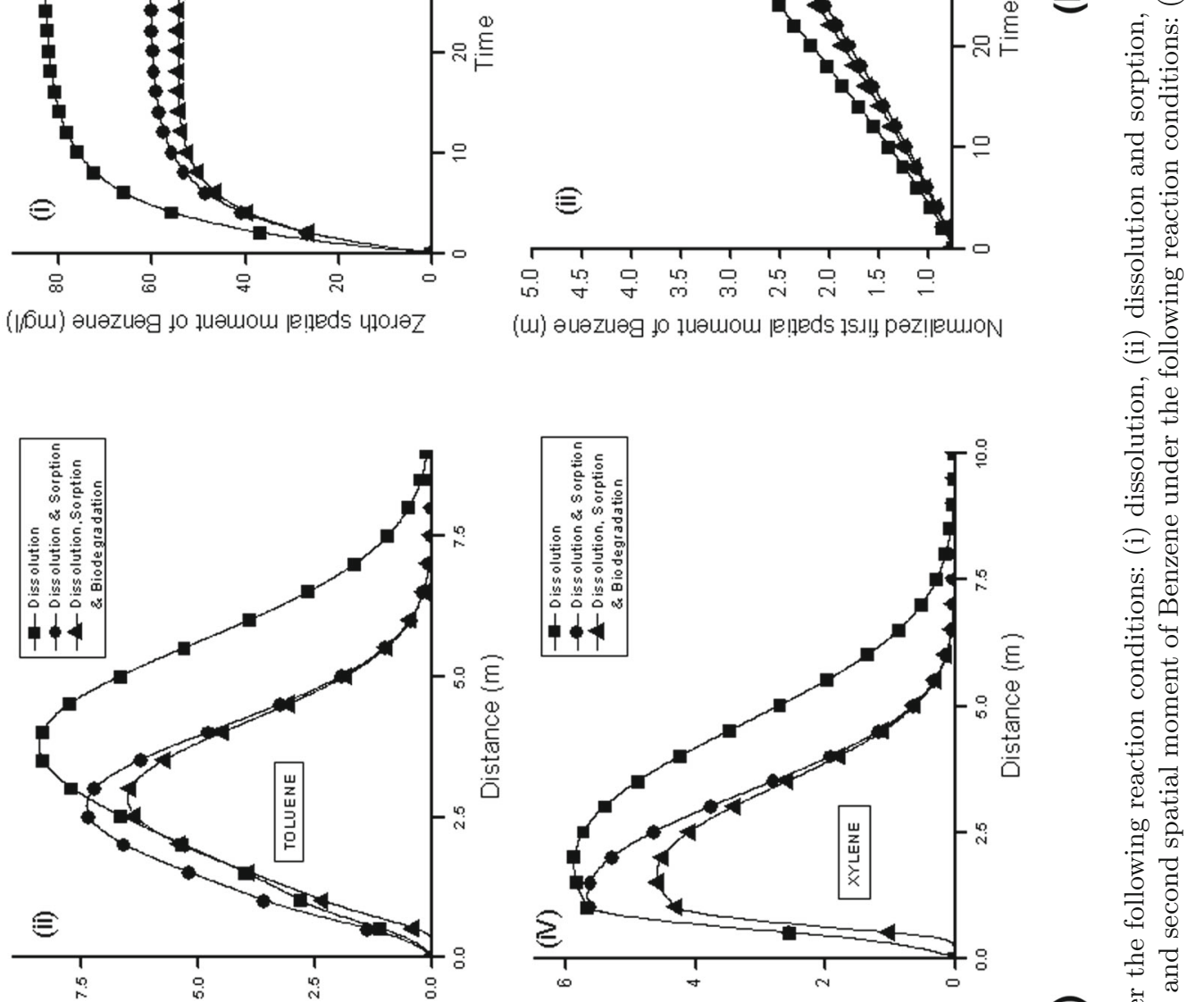

(///6u) uo!̣ed\}uəsuos snoanby

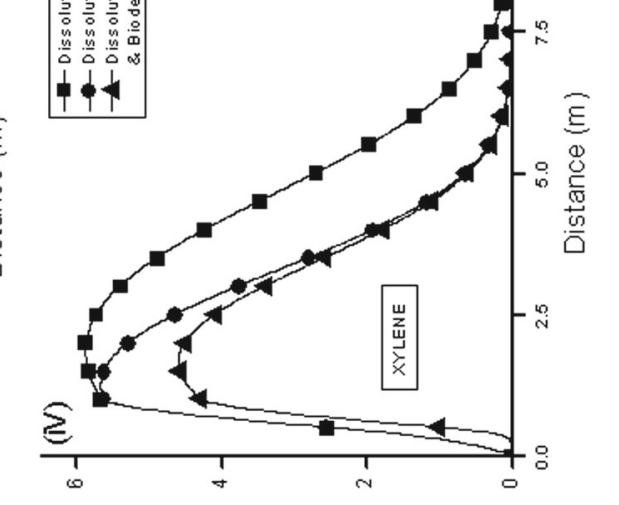

(|/бu) uo!̣e-дuəsuos snoenby
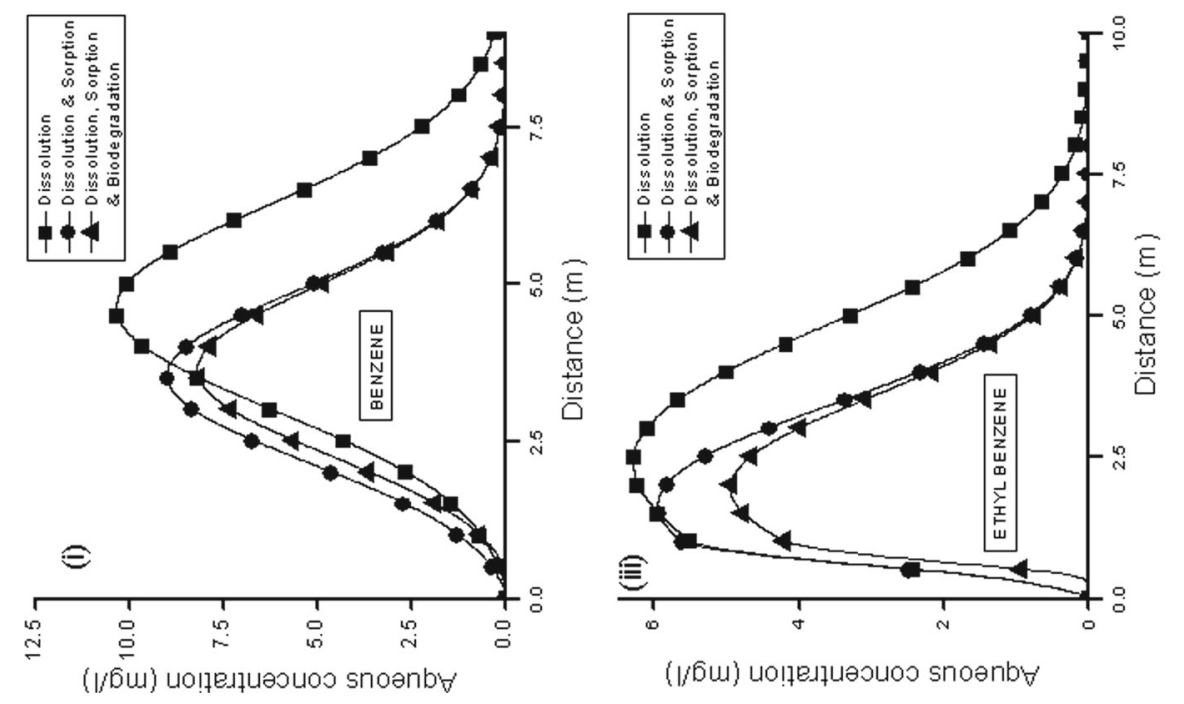

ฮี

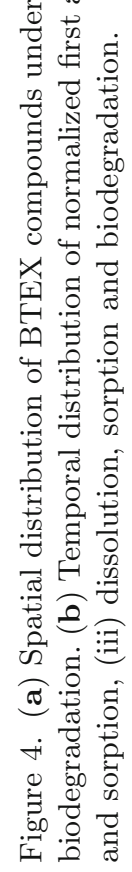




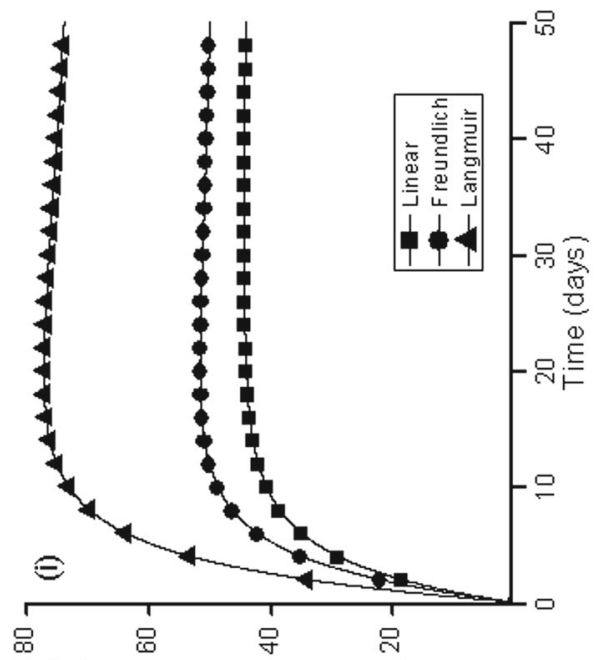

(1/6u) auazuag to tuamou |e!̣eds ytodaz

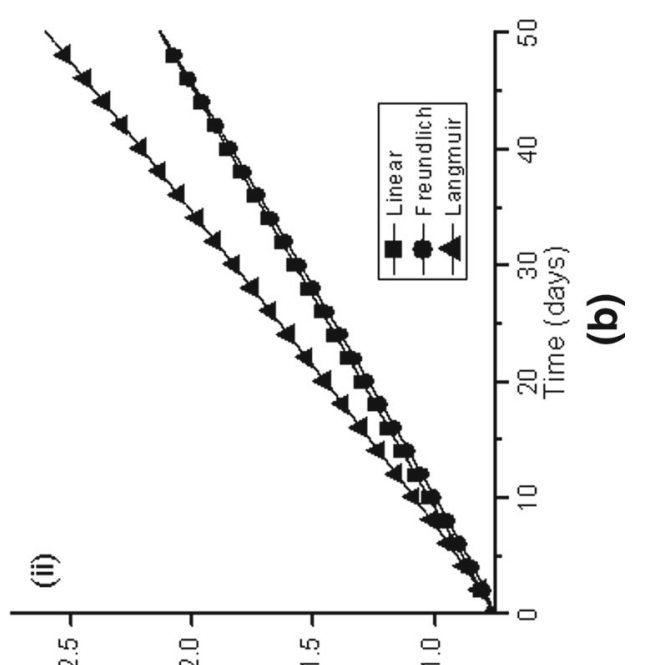

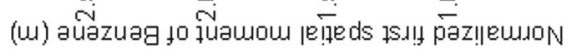
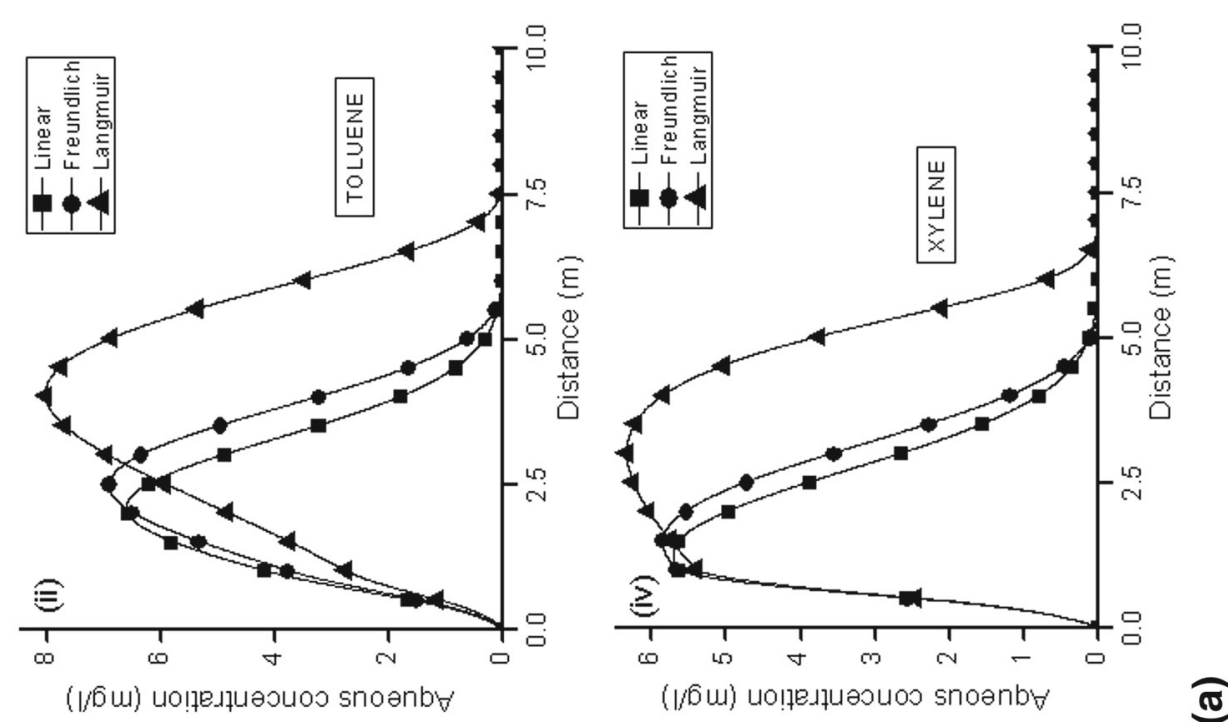

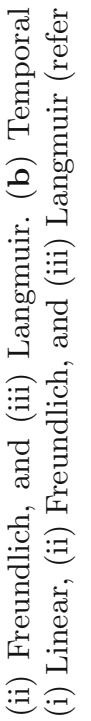

苞

$\approx . \mathbb{2}$



究

贾

อี

을

औ

寻

:

Sol

范

을

$\stackrel{乛}{\ddagger}$ के

(ㄷ)
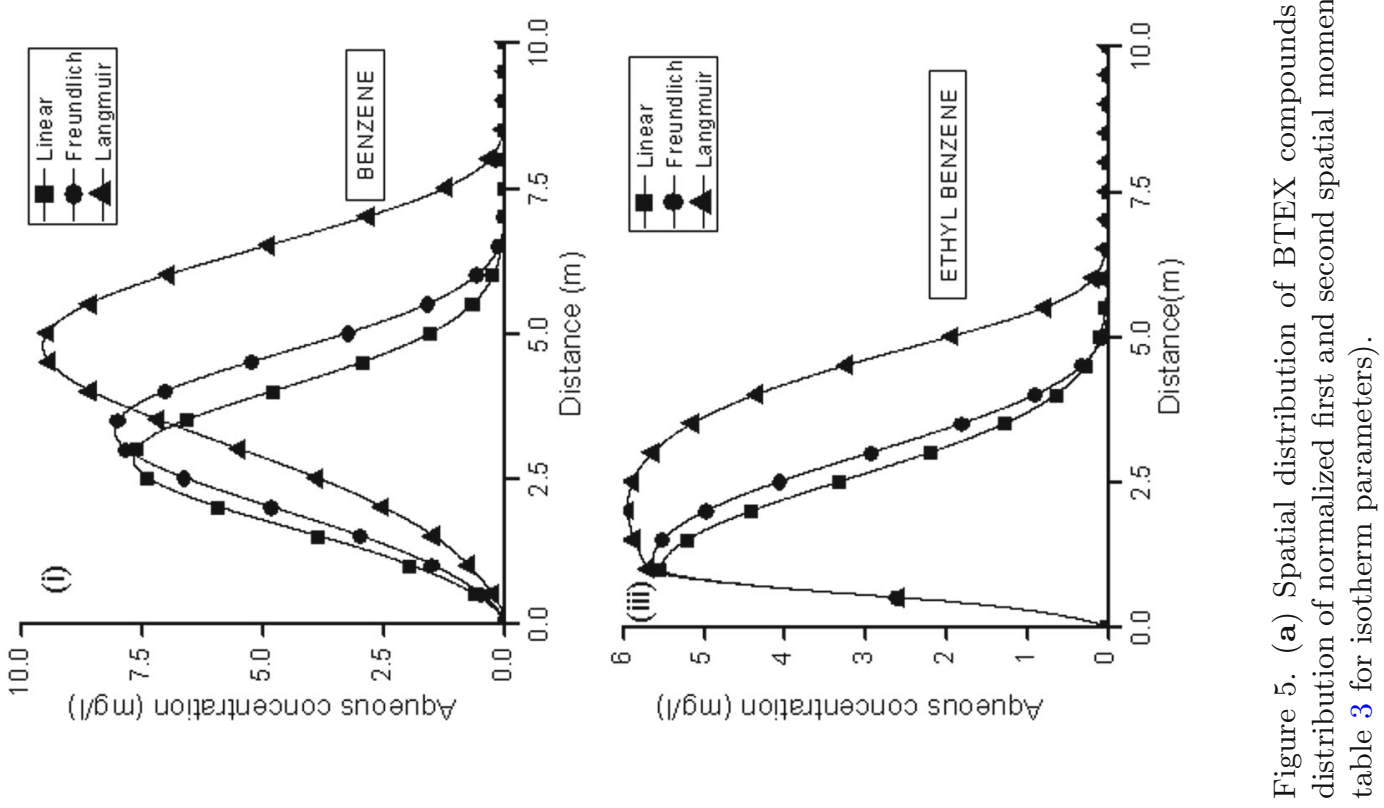
Table 3. Biodegradation parameters of LNAPL components considered for simulation.

\begin{tabular}{lcccc}
\hline $\begin{array}{l}\text { LNAPL } \\
\text { component }\end{array}$ & $\begin{array}{c}\text { Half saturation } \\
\text { constant, } K_{s}(\mathrm{~kg} / \mathrm{L})\end{array}$ & $\begin{array}{c}\text { Maxim substrate } \\
\text { utilization rate }\left(\text { day }^{-1}\right)\end{array}$ & Yield & Reference \\
\hline Benzene & 2 & 0.5 & 0.5 & Molson et al. $(2002)$ \\
Toluene & 2 & 0.5 & 0.5 & Molson et al. $(2002)$ \\
Ethyl Benzene & 2 & 0.5 & 0.5 & Molson et al. $(2002)$ \\
Xylene & 2 & 0.5 & 0.5 & Molson et al. $(2002)$ \\
Oxygen & 2 & 0.5 & 0.5 & Molson et al. $(2002)$ \\
\hline
\end{tabular}

sorption isotherm parameters are adopted in such a way that the effective retardation coefficient remains same for all three isotherms. It can be observed from figure 5(a) that till the peak value of the dissolved BTEX concentration is reached, concentration profiles of dissolved BTEX components are not very sensitive to sorption isotherms. This is due to the higher dissolution rate from the LNAPL source zone. Hence, the concentration distribution of dissolved BTEX components is not sensitive to equilibrium sorption isotherms till the BTEX components reach the source zone. It can also be noted from figure 5(a) that for all four BTEX components, Langmuir sorption provided least retardation effect. This may be due to the non-availability of sorption sites for Langmuir sorption isotherms. Further, it can be seen from figure 5(a) that favourable Freundlich sorption and linear sorption interact with the dissolution mass transfer of BTEX compounds in similar manner.

Figure 5(b) shows the temporal variation of zeroth spatial moment and normalized first spatial moment of Benzene for same data shown in figure 5(a). First plot of figure $5(\mathrm{~b})$ provides the temporal variation of zeroth spatial moment of Benzene. It can be noted from figure $5(\mathrm{~b})$ that the dissolved mass of Benzene within the system is more for Langmuir sorption isotherm and is least for Freundlich sorption isotherm. It can also be seen from figure 5(b) that the dissolved mass of Benzene is sensitive to equilibrium sorption isotherm only after total simulation period of 10 days. Second plot of figure 5(b) provides the temporal variation of normalized first spatial moment of Benzene. It can be seen from figure 5(b) that the effective velocity of Benzene is higher in case of Langmuir sorption isotherm and least in the case of the Freundlich sorption isotherm. Higher mobility of Benzene is due to the less retardation in case of Langmuir sorption isotherm. Mobility of Benzene in case of linear sorption is less than that in case of Langmuir sorption and slightly higher than that in case of favourable Freundlich sorption. Further, it can be noted from figure 5(b) that the profiles are linear, indicating time independent velocity in case of all the three equilibrium sorption isotherms.

\subsection{Influence of sorption kinetics on BTEX transport}

Figure 6(a) provides the spatial distribution of dissolved concentration of BTEX components for sorption kinetics with various mass transfer rates. It can be seen from figure 6(a) that, the peak dissolved concentration of all four BTEX components is reducing with an increase in sorption mass transfer rate. It can be observed from figure 6(a) that unlike in case of equilibrium sorption isotherms, sorption kinetics is affecting peak and ascending limbs of aqueous concentration profiles of BTEX component with higher solubility. Whereas, for less soluble BTEX components (Ethyl Benzene and Xylene), sorption kinetics is affecting dissolution mass transfer only after the dissolved BTEX components reach the residual BTEX source zone. In case of highly soluble component, reduction in dissolved concentration due to sorption kinetics is not compensated by the dissolution mass transfer. Further, it can be noted that for other two cases of sorption mass transfer rates $(\xi=0.001 \mathrm{~m} / \mathrm{d}$ and $\xi=0.0005 \mathrm{~m} / \mathrm{d}$ ), dissolved concentration profiles of all the four BTEX components match closely. This indicates that, when sorption mass transfer rate is low the dissolution mass transfer is not very sensitive to sorption mass transfer rate.

Figure 6(b) shows the temporal variation of zeroth spatial moment and first normalized spatial moment of Benzene for the data shown in figure 6(a). First plot of figure $6(\mathrm{~b})$ provides the temporal variation of zeroth spatial moment of Benzene for different sorption mass transfer rates. It can be seen from figure 6(b) that for higher mass transfer rate $(\xi=0.005 \mathrm{~m} / \mathrm{d})$, dissolved mass of Benzene increases initially, attains a peak value and 

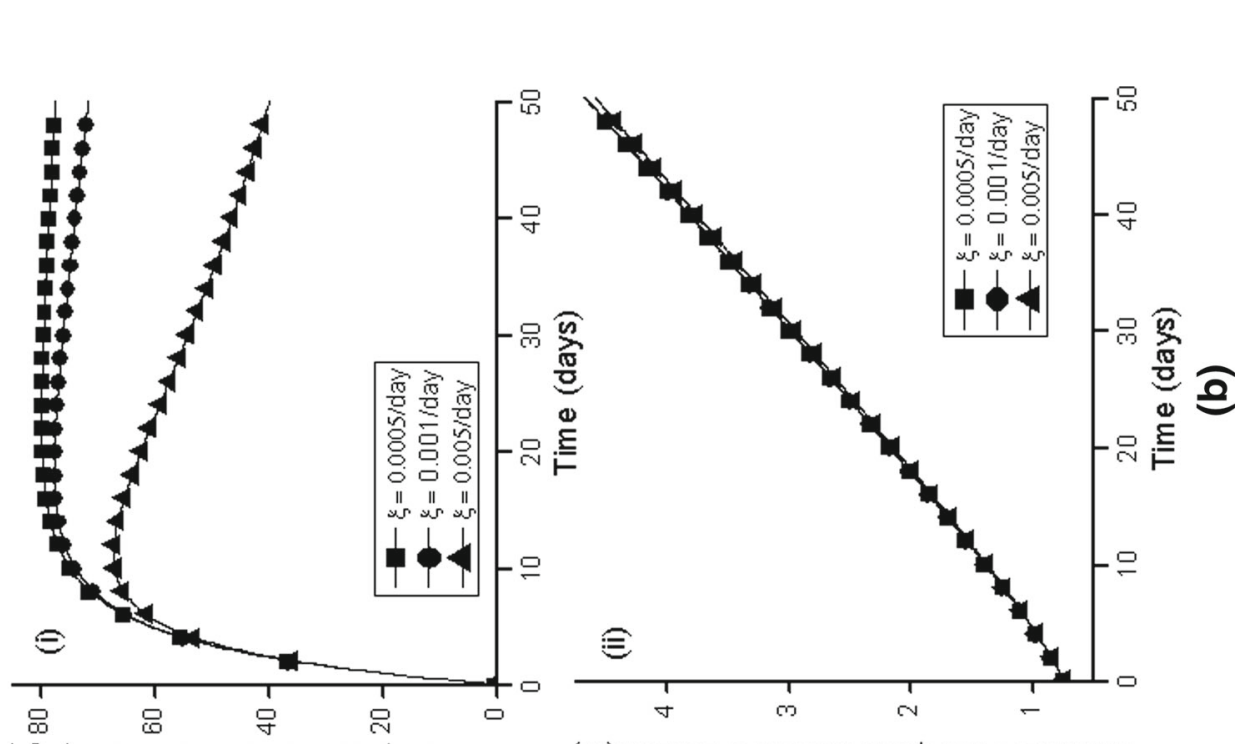

:

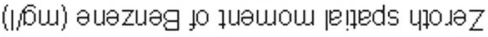

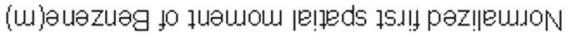
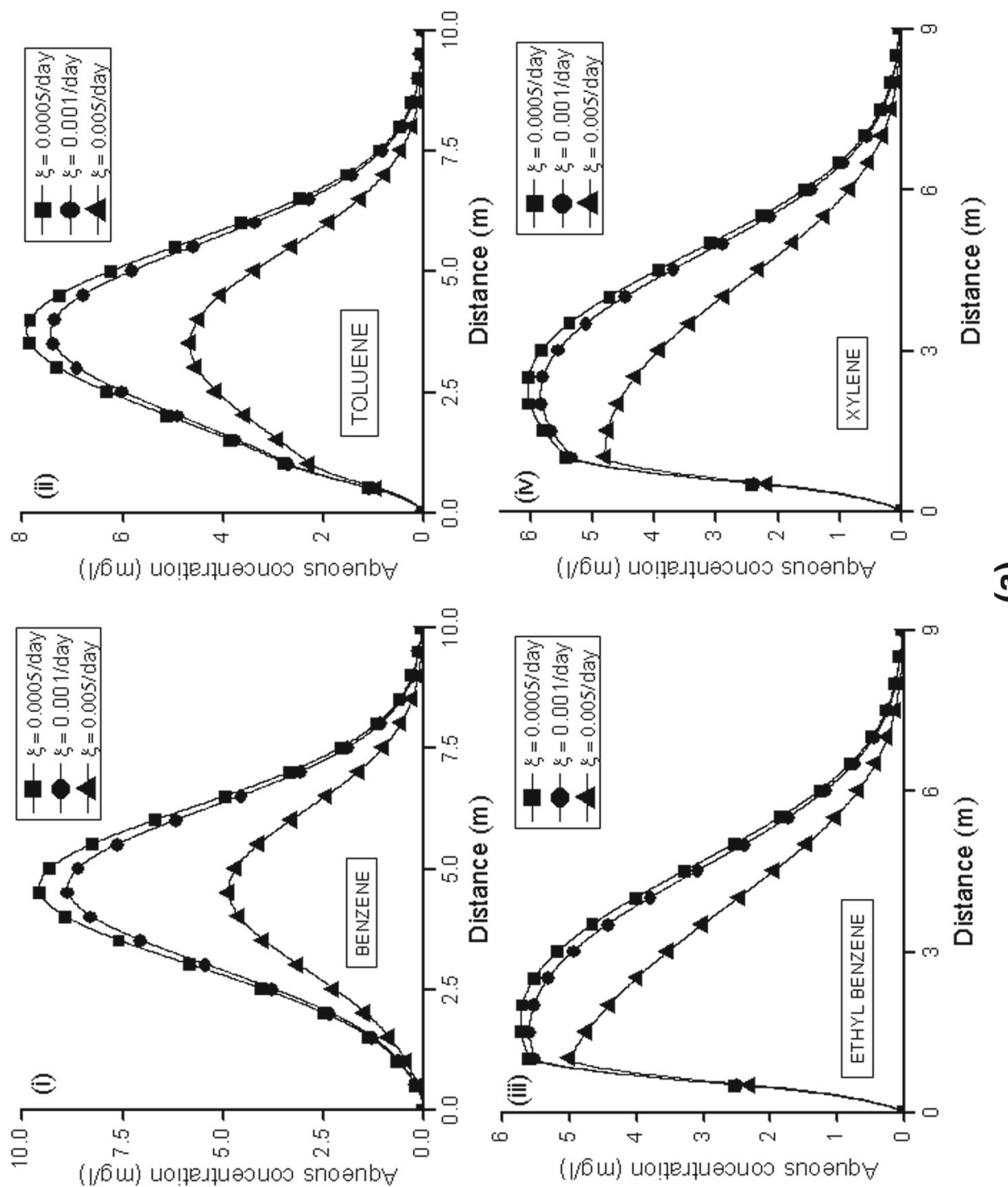

范

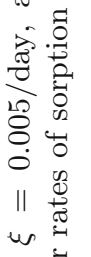

$\approx \frac{\vec{v}}{\vec{w}}$

完

ㄷำ

8 .

용

u

$\approx$ :

包

娄

원

菅

它

पै

के

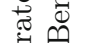

जे

जै

\pm घ

跑

छี. .

bo

范

융

$\frac{1}{\square} 0$

(3)

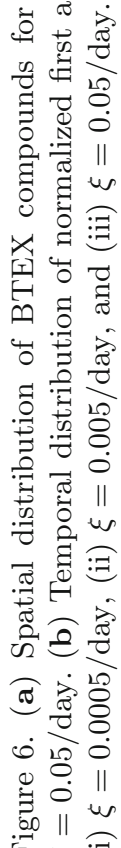


reduces thereafter. Further, it can be seen from figure $6(\mathrm{~b})$ that as mass transfer rate of sorption kinetics reduces, dissolution mass transfer tends to reach steady state earlier. Second plot of figure 6(b) provides the temporal variation of normalized first spatial moment. It can be seen from figure 6(b) that mobility of Benzene is not sensitive to sorption mass transfer rate. Linear variation of normalized first spatial moment indicates that the mobility of Benzene is time independent for dissolution transfer under sorption kinetics.

\subsection{Influence of residual source zone length on BTEX transport}

Figure 7 illustrates the effect of variation of source zone length on spatial distribution of dissolved BTEX components and on the temporal variation of zeroth and normalized first spatial moment of Benzene under dissolution mass transfer. Figure 7(a) provides the spatial variation of dissolved Benzene, Toluene, Ethyl Benzene and Xylene concentrations for different lengths of source zone. In all three cases of simulation, same mass of BTEX compounds is considered for analysis. As it is clear from figure $7(\mathrm{a})$, dissolution mass transfer from the BTEX source zone increases with increase in source zone length. Further, it can be noted that peak aqueous concentration of all the four BTEX components increases with increases in source zone length. When components spread along more length, more dissolution mass transfer happens from the BTEX source zone to the groundwater due to the existence of concentration gradient for longer distance. It can be further noted that, peak aqueous concentration of all the four BTEX components are shifting away from the left boundary with increase in length of source zones.

Figure $7(\mathrm{~b})$ shows the temporal variation of zeroth spatial moment or normalized first spatial moment of Benzene for same data shown in figure $7(\mathrm{a})$. First plot of figure $7(\mathrm{~b})$ provides the temporal variation of zeroth spatial moment of Benzene for different lengths of BTEX source zones. As it is clear from figure $7(\mathrm{~b})$, aqueous concentration mass of Benzene is increasing with increase in length of source zones. It can also be noted from figure $7(\mathrm{~b})$ that time required to attain steady state dissolution mass transfer is reducing with increase in source zone length. Second plot of figure $7(\mathrm{~b})$ shows the temporal variation of first spatial moment of Benzene for different lengths of source zones. It can be seen from figure 7(b) that for all the three cases of source zones, velocity of Benzene almost remains same. Linear variation of normalized first spatial moment indicates that the mobility of Benzene is time independent for all three cases of source zone length.

\subsection{Influence of inlet dissolved oxygen concentration on BTEX transport}

Figure 8 illustrates the effect of variation of inlet oxygen concentration (electron acceptor) on the aqueous concentration distribution and the temporal variation of zeroth and first normalized spatial moment under dissolution mass transfer and aerobic biodegradation. In figure 8, simulation results are presented for the inlet dissolved oxygen concentration varying from 0.1 to $10 \mathrm{mg} / \mathrm{l}$. The dissolved oxygen concentration in the groundwater aquifers is usually below $1 \mathrm{mg} / \mathrm{l}$ (Winograd and Robertson 1982; Rose 1987). However, few research investigations have shown that the dissolved oxygen concentration within the groundwater aquifer can be more than $1 \mathrm{mg} / \mathrm{l}$ under the following circumstances: (1) depth of the water table from the ground surface is low, (2) oxygen gets transported effectively from the vadose zone to the saturated zone, (3) limited microbial degradation in the aquifer, (4) low temperature in the aquifer (Rose and Long 1988). Thus, the dissolved oxygen concentration within the aquifer can be varied by the hydrogeological conditions existing at the site. Figure 8(a) provides the spatial variation of aqueous concentration of BTEX components. It is seen from figure 8 that when there is an increase in the dissolved oxygen concentration from 0.1 to $1 \mathrm{mg} / \mathrm{l}$, there is no significant change in the dissolved concentration of BTEX components. However, when dissolved oxygen concentration rises from 1 to $10 \mathrm{mg} / \mathrm{l}$, there is significant reduction in the concentration of dissolved BTEX concentration. The simulation case presented in figure 8 for dissolved oxygen concentration of $10 \mathrm{mg} / \mathrm{l}$ shows that the increase in the supply of dissolved oxygen at the aquifer inlet will help to reduce the dissolved concentration of BTEX components considerably. This implies that the effect of biodegradation on BTEX migration is less significant in case of low values of dissolved oxygen concentration. As it is clear from figure 8(a), increase in inlet electron acceptor concentration is causing significant reduction in dissolution mass transfer during ascending 

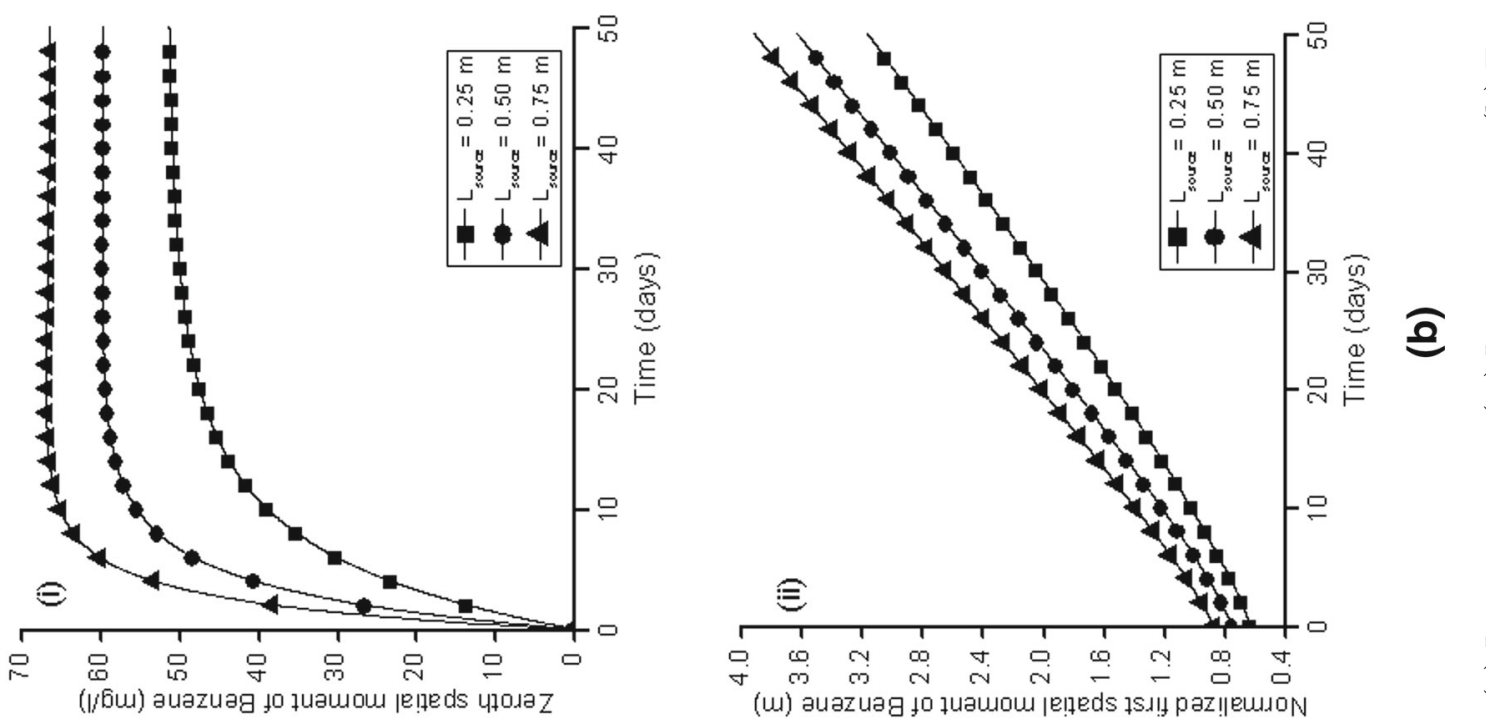

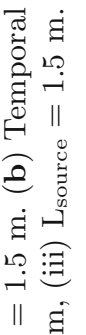
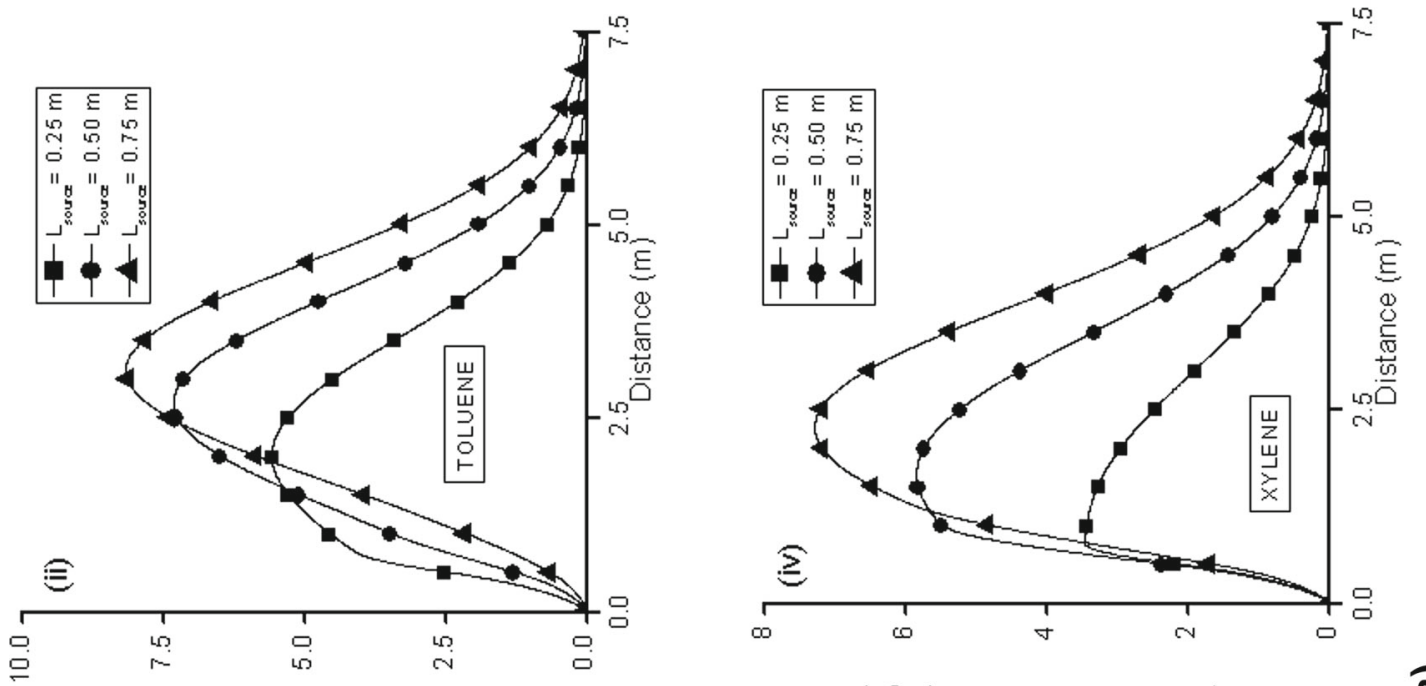

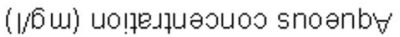

(//6u) uo!̣eגpuəouos snoənby
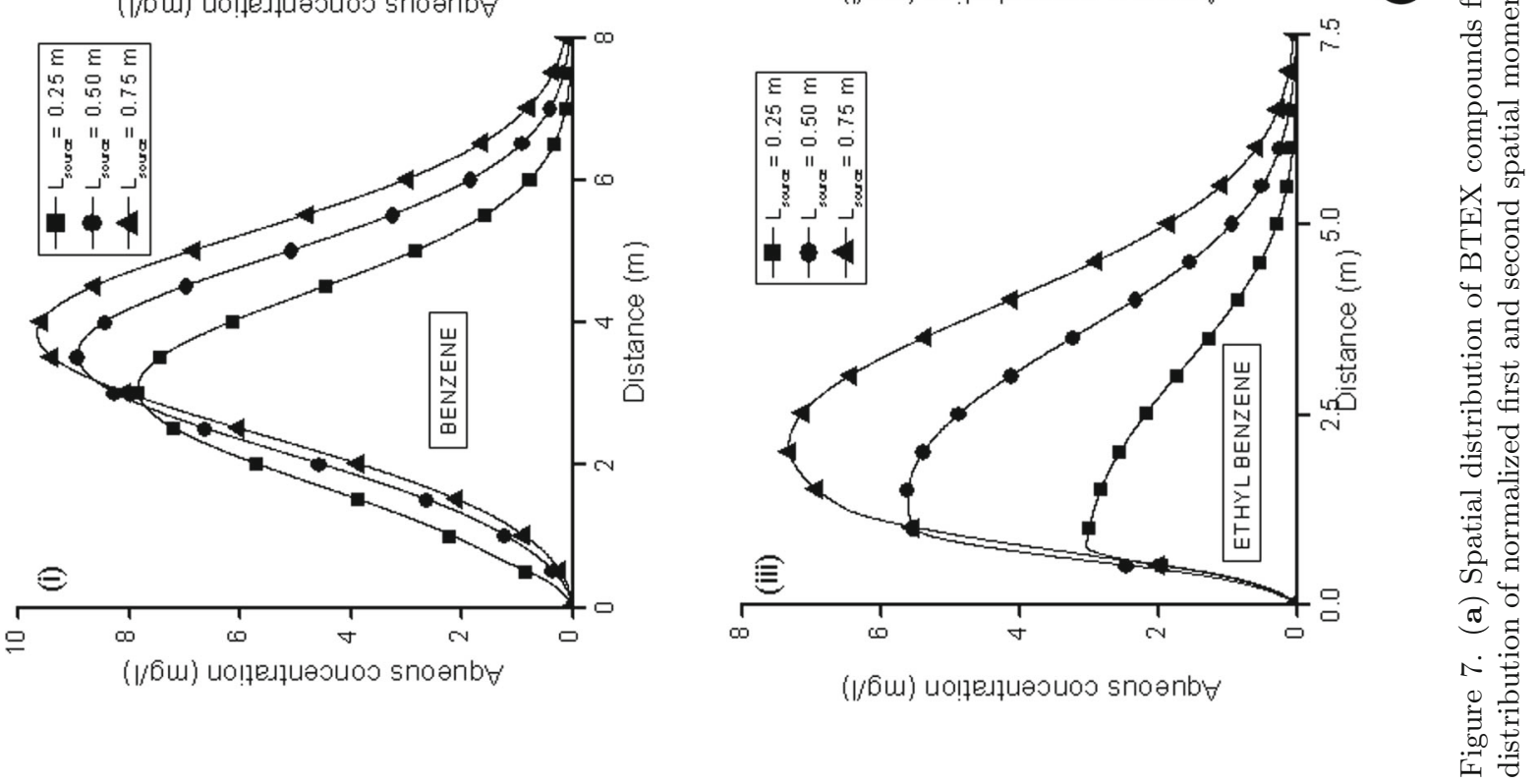


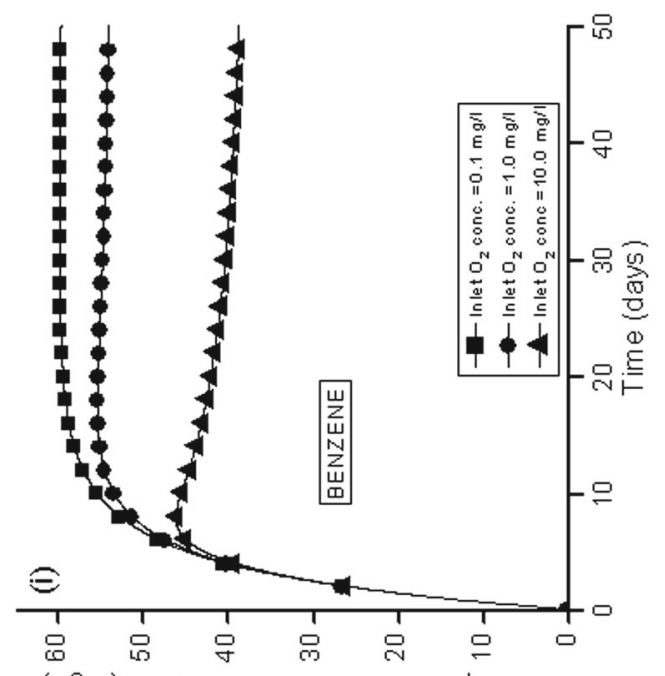

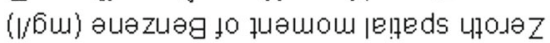

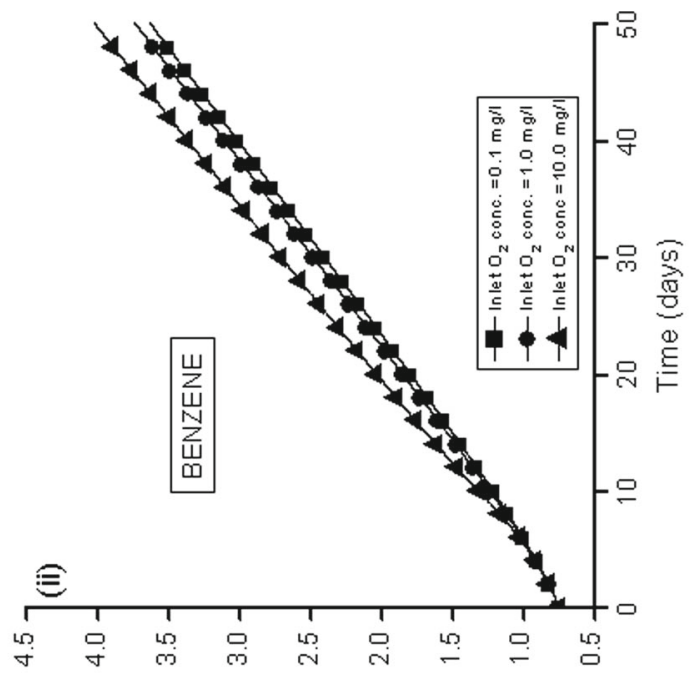

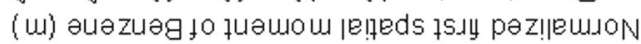


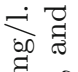

$\stackrel{2}{\stackrel{\infty}{\infty}}$

:ᄏન

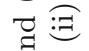

$\overbrace{\infty 0}^{\infty}$

อ

$\stackrel{\square}{\neg}$

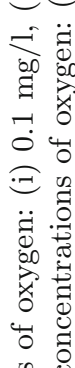

告

త్ర

용

D

:

苛

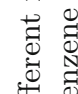

苟

०ै

를

龸

(I)

ก

무류

焉

귱

पे

궁

궁

责

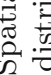

๙

읍으

站 0 : 
limb and peak value of the aqueous concentration profile. Descending limbs of aqueous concentration profiles are not sensitive to inlet dissolved oxygen concentration due to the absence of biodegradation reaction at that location. From figure 8(a), it can be observed that the peak dissolved concentrations of BTEX components is reducing with increase in inlet concentration. Dissolved oxygen (electron acceptor) may not reach away from the left boundary and absence of dissolved oxygen will lead to absence of aerobic biodegradation. Hence dissolution mass transfer of BTEX components will be insensitive to inlet oxygen concentration away from left boundary. Further, it can be noted from figure 8(a) that, irrespective of the inlet concentration value of electron acceptor, the influence of biodegradation exists for the same domain length in all three cases. It can also be seen from figure 8(a) that biodegradation is causing more reduction in dissolved concentration of a component with least solubility in a BTEX mixture.

Figure 8(b) shows the temporal variation of zeroth spatial moment and normalized first spatial moment of Benzene for the same data shown in figure 8(a). First plot of figure 8(b) shows the temporal variation of zeroth spatial moment for different values of inlet dissolved oxygen concentrations. It can be noted from figure 8(b) that the concentration profile of dissolved Benzene is not significantly affected by the inlet oxygen concentration initially. Biodegradation starts affecting the dissolution mass transfer approximately after a total simulation period of 10 days. It can be observed from figure $8(\mathrm{~b})$ that dissolved Benzene mass is significantly getting reduced with increase in inlet oxygen concentration. It can be seen from figure $8(\mathrm{~b})$ that for low inlet oxygen concentration, dissolved Benzene mass in the aquifer reaches steady state. As inlet oxygen concentration increases, dissolved Benzene mass in the domain will start slightly reducing after reaching the peak. Hence, from figure $8(\mathrm{~b})$ it can be inferred that as inlet oxygen increases, time required to reach steady-state dissolution mass transfer increases. Second plot of figure 8(b) provides temporal variation of normalized first spatial moment of Benzene for different inlet oxygen concentrations. As it is clear from figure $8(\mathrm{~b})$, mobility of Benzene is not very sensitive to the inlet oxygen concentration. It can also be seen from figure $8(\mathrm{~b})$ that the mobility of Benzene is slightly reducing with increase in inlet dissolved oxygen concentration.
This reduction in mobility is due to reduction in dissolved concentration resulting from the mass removal due to dissolution.

\section{Summary and conclusions}

In the present study, multi-component dissolution mass transfer from a BTEX residual source zone under the influence of sorption and biodegradation is studied. Influence of equilibrium and kinetic controlled sorption conditions on dissolved BTEX component transport is also investigated. Numerical modeling is combined with lower order spatial moment analysis to investigate the influence of interaction of various transport processes on total dissolved mass and mobility of BTEX components. The following conclusions can be drawn from the present study

- Sorption retards the transport of dissolved BTEX components only after the source zone location and the sorption is also found to significantly reduce the peak of dissolved BTEX concentration significantly. Sorption causes a reduction in the total dissolved mass and mobility of BTEX within the aquifer.

- Aerobic biodegradation influences the migration of dissolved BTEX only till the extent of migration of dissolved oxygen and the influence of biodegradation on dissolved BTEX plume migration is found to be more near the left aquifer boundary. Biodegradation is also found to affect the peak of dissolved BTEX concentration, whereas the total dissolved mass and mobility of BTEX within the aquifer is found to be not sensitive to biodegradation.

- Adopting Langmuir sorption relationship for modeling equilibrium sorption may overestimate the concentration of dissolved BTEX concentration within the aquifer compared to linear and Freundlich sorption isotherms. Dissolved mass and mobility of BTEX components are also found to be more in case of Langmuir sorption isotherm. Thus it can be concluded that the selection of appropriate isotherm relationship is very important in the transport modeling of dissolved BTEX components.

- The kinetic sorption rate is found to be affecting the transport of dissolved Benzene (the most soluble component in the BTEX) the most. The influence of kinetic sorption rate on the transport of Xylene (the least soluble component in BTEX) is found to be the lowest. Extent of 
dissolved BTEX plume is found to be insensitive to kinetic sorption rate, whereas the total dissolved mass of BTEX components are found to reduce with increase in kinetic sorption rate.

- Dissolved BTEX concentrations are found to increase with increase in length of the source zone. Increase in source zone length is found to be increasing the total dissolved mass of BTEX components, whereas the mobility of dissolved BTEX components are found to be not affected by the BTEX source zone length.

- Increase in the inlet dissolved oxygen concentration is found to significantly reduce the ascending limb and peak of dissolved BTEX concentration profiles. Increase in dissolved oxygen concentration is also found to reduce the mass of dissolved BTEX components significantly, whereas the mobility of dissolved BTEX components is found to be insensitive to inlet dissolved oxygen concentration.

In the present study, the model structure is formulated by considering the transport processes (multi-component dissolution, sorption and biodegradation) to occur simultaneously at all-time levels. In reality, these transport processes may not have a predominant role on the migration of BTEX at all-time levels. Hence, the relative importance of these transport processes on the concentration of dissolved BTEX components may vary from time to time. However, incorporating this time varying significance of the transport processes into the model will be challenging due to the lack of understanding of these processes. Thus, the incomplete understanding of the transport processes will lead to an uncertainty in predicting the concentration distribution of BTEX components. Moreover, the uncertainty in the parameter selections for modeling flow, dissolution, biodegradation and sorption may also contribute to some amount of uncertainty in model predictions. In addition, the selection of numerical approximation schemes and the grid and time resolution of the model will also cause some amount of model uncertainty. However, in the present study the uncertainties arising from all the above-mentioned aspects are assumed not to affect the final model results.

The present modeling study can be used as a preliminary tool to predict the long term interaction of the natural attenuation processes occurring in a saturated aquifer with residual spill of petroleum hydrocarbons. This study can be extended to other multi-component LNAPL or
DNAPL residual source zones in saturated aquifers. These investigation results are useful in suggesting the remediation techniques to enhance the depletion rate of residual source zones.

\section{Appendix}

\section{A1. Equilibrium sorption isotherms}

Under equilibrium conditions, distribution of adsorbed molecules between the liquid phase and solid phase is indicated by sorption isotherm. But based on the variation in interaction as the flow regime progresses, sorption isotherm can be linear or non-linear. For equilibrium sorption isotherm, the sorption effect is given by the instantaneous retardation factor.

\section{A2. Linear sorption isotherm}

For linear sorption, sorbed concentration, $S\left(\mathrm{MM}^{-1}\right)$ and aqueous concentration of solutes, $C\left(\mathrm{ML}^{-3}\right)$ are related as expressed in equation (A.1)

$$
S=K_{d} C
$$

The retardation factor for linear sorption can be computed as provided in equation (A.2)

$$
R_{f}=1+\frac{\rho_{b} K_{d}}{\theta}
$$

In equation (A.2), $K_{d}$ represents the distribution coefficient $\left(\mathrm{L}^{3} \mathrm{M}^{-1}\right), \rho_{b}$ represents the mass density of aquifer material $\left(\mathrm{ML}^{-3}\right)$.

\section{A3. Freundlich non-linear sorption isotherm}

Among non-linear sorption isotherms, Freundlich sorption isotherm is the most commonly used isotherm (Weber et al. 1991) to describe sorption in heterogeneous surfaces. In Freundlich isotherm, it is assumed that the concentration of adsorbate increases with the concentration of adsorbate on the adsorbent surface (Freundlich 1906; Quintelas et al. 2008). As per Freundlich isotherm, sorbed concentration and aqueous concentration are related as provided in equation (A.3)

$$
S=K_{f} C^{n} .
$$

In equation (A.3), $C$ represents the volume concentration of solute $\left(\mathrm{ML}^{-3}\right), S$ represents the 
sorbed concentration $\left(\mathrm{MM}^{-1}\right), K_{f}$ represents the Freundlich coefficient $\left(\mathrm{L}^{3} \mathrm{M}^{-1}\right)$ and $n$ represents the Freundlich sorption intensity, $n$ normally varies between 0.7 and 1.2. The retardation factor for Freundlich isotherm in porous media can be computed as provided in equation (A.4)

$$
R_{f}=1+\frac{n \rho_{b} K_{f}}{\theta} C^{n-1} .
$$

In equation (A.4), $\rho_{b}$ represents the bulk density of aquifer material $\left(\mathrm{ML}^{-3}\right)$.

\section{A4. Langmuir non-linear sorption isotherm}

Another commonly used non-linear isotherm is introduced by Langmuir (1918). Langmuir isotherm assumes a monolayer coverage of adsorbate or homogeneous subsurface. In Langmuir non-linear isotherm, relationship between sorbed concentration and aqueous concentration are given as in equation (A.5)

$$
S=Q_{\max } b C /(1+b C) .
$$

In equation (A.5), $S$ represents the sorbed concentration $\left(\mathrm{MM}^{-1}\right), Q_{\max }$ represents the maximum Langmuir sorption capacity $\left(\mathrm{MM}^{-1}\right), b$ represents the Langmuir constant $\left(\mathrm{L}^{3} \mathrm{M}^{-1}\right)$.

The retardation factor for Langmuir sorption isotherm can be deduced as provided in equation (A.6).

$$
R_{f}=1+\frac{\rho_{b} Q_{\max } b}{\theta(1+b C)^{2}}
$$

where $\rho_{b}$ is the bulk density of aquifer material $\left(\mathrm{ML}^{-3}\right)$ and $\theta$ is the porosity.

\section{References}

Atteia O and Guillot C 2007 Factors controlling BTEX and chlorinated solvents plume length under natural attenuation conditions; J. Contam. Hydrol. 90 81-104.

Borden R C and Piwoni M D 1992 Hydrocarbon dissolution and transport: A comparison of equilibrium and kinetic models; J. Contam. Hydrol. 10 309-323.

Clement T, Gautam T, Lee K, Truex M and Davis G 2004 Modeling of DNAPL-dissolution, rate-limited sorption and biodegradation reactions in groundwater systems; Bioremed. J. 8(1-2) 47-64.

Corey A T 1986 Mechanics of immiscible fluids in porous media; Water Resources Publication, Fort Collins, Colorado.
Derrick O N, Stephen A A and Peter C U 2005 The dissolution rate of BTEX components in water; Canadian. J. Chem. Eng. 83 985-989.

Essaid H I, Cozzarelli M I, Eganhouse P R, Herkelrath W N, Belkins B A and Delin G N 2003 Inverse modeling of BTEX dissolution and biodegradation at the Bemidgi, M-N crude-oil spill site; J. Contam. Hydrol. 67 269-299.

Ezzedine S and Rubin Y 1997 Analysis of the Cape Cod tracer data; Water Resour. Res. 33 1-11.

Freundlich H 1996 Adsorption in solution; J. Phys. Chem. $57384-410$.

Frind E O, Molson J W, Schirmcr M and Guiguer N 1999 Dissolution and mass transfer of multiple organics under field conditions: The Borden emplaced source; Water Resour. Res. 35 683-694.

Gelhar L W 1993 Stochastic subsurface hydrology; Prentice Hall, Prentice Hall, NJ, USA, pp. 184-194.

Goltz M N and Roberts P V 1987 Using the method of moments to analyze three-dimensional diffusion-limited solute transport from temporal and spatial perspectives; Water Resour. Res. 23 1575-1585.

Govindarajau R S and Das B S 2007 Moment analysis for sub-surface hydrologic applications, Springer, Dordrecht, The Netherlands, pp. 143-153.

Guven O, Molz F J and Melville J G 1984 An analysis of dispersion in a stratified aquifer; Water Resour. Res. 20 1337-1354.

Hamed M M, Nelson P D and Bedient P B 2000 A distributed site model for non-equilibrium dissolution of multicomponent residually trapped NAPL; Environ. Model. Soft. 15 443-450.

Imhoff P T, Arthur M, and Miller C T 1994 An experimental study of complete dissolution of a non-aqueous phase liquid in saturated porous media; Water Resour. Res. 30 307-320.

Javandel I 1996 Evaluation of transient dissolution of slightly water-soluble compounds from a light non aqueous phase liquid pool; Water Resour. Res. 32 915-923.

Langmuir I 1918 Adsorption of gases on plane surfaces of glass, mica and platinum; J. Am. Chem. Soc. 40(9) 13611403.

Lu G, Clement P T, Zheng C and Wiedemeier H T 1999 Natural attenuation of BTEX compounds: Model development and field-scale applications; Ground Water $\mathbf{3 7}$ 707-717.

Molson J W, Frind E O, van Stempvoort D R and Lesage S 2002 Humic acid-enhanced remediation of an emplaced diesel source in groundwater 2: Numerical model development and application; J. Contam. Hydrol. 54 277-305.

Nambi I M and Powers S E 2003 Mass transfer correlations for non-aqueous phase liquid dissolution from regions with high initial saturations; Water Resour. Res. 39 1-11.

Ojuri O O and Ola S A 2010 Estimation of contaminant transport parameters for a tropical sand in a sand tank model; Int. J. Environ. Sci. Tech. 7 385-394.

Ordencrantz J E, Valocchi A J and Rittman B E 1993 Modeling the interaction of sorption and biodegradation on transport in groundwater in situ bioremediation systems; Proceedings of the Groundwater Modeling Conference, Golden Colorado.

Powers S E, Abriola L M and Weber Jr W J 1994 An experimental investigation of NAPL dissolution in saturated 
subsurface systems: Transient mass transfer rates; Water Resour. Res. 30 321-332.

Prommer H, Barry D A and Davis G B 1999 A onedimensional reactive multi-component transport model for biodegradation of petroleum hydrocarbons in groundwater; Environ. Model. Soft. 14 213-223.

Prommer H, Davis G B and Barry D A 2000 Biogeochemical transport modeling of natural and enhanced remediation processes in aquifers; Land Contam. Reclam. 8(3) 217223.

Quintelas C B, Fernandes J C, Figueiredo H and Tavares T 2008 Biosorption of Cr (VI) by three different bacterial species supported on granular activated carbon - A comparative study; J. Hazard. Mater. 153 799-809.

Renu V and Suresh Kumar G 2012 Numerical modeling and spatial moment analysis of solute mobility and spreading in a coupled fracture-skin-matrix system; Geotech. Geolog. Eng. 30 1289-1302.

Renu V and Suresh Kumar G 2014 Temporal moment analysis of solute transport in a coupled fracture-skin-matrix system; Sadhana 39 487-509

Rose S 1987 Dissolved oxygen systematics in the Tucson basin aquifer ( $\mathrm{PhD}$ Dissertation), University of Arizona, Tucson, Arizona, 161p.

Rose S and Long A 1988 Monitoring dissolved oxygen in ground water: Some basic considerations; Ground Water Monit. R. 8(1) 93-97.

Rivett M O and Allen-King R M 2003 A controlled field experiment on groundwater contamination by a multicomponent DNAPL: Dissolved-plume retardation; J. Contam. Hydrol. 66 117-146.
Saba T and Illangasekare T H 2000 Effect of groundwater flow dimensionality on mass transfer from entrapped nonaqueous phase liquid contaminants; Water Resour. Res. 36(4) 971-979.

Schaerlaekens J, Vanderborght J, Merckx R and Feyen J 2000 Surfactant enhanced solubilization of residual trichloroethene: An experimental and numerical analysis; J. Contam. Hydrol. 46 1-16.

Sekhar M and Suresh Kumar G 2005 Modeling transport of linearly sorbing solutes in a single fracture: Asymptotic behavior of solute velocity and dispersivity; Geotech. Geolog. Eng. 24 183-201.

Site A D 2001 Factors affecting sorption of organic compounds in natural sorbent water systems and sorption coefficients for selected pollutants; A review; J. Phys. Chem. Ref. Data 30(1) 187-439.

Vasudevan M, Suresh Kumar G and Nambi I M 2012 Effect of rate limited dissolution and sorption on concentration tailing of multi-component petroleum hydrocarbons from residual sources; Int. J. Earth Sci. Engg. 6(1) 750-1756.

Vasudevan M, Suresh Kumar G and Nambi I M 2014 Effect of rate limited dissolution and sorption on concentration tailing of multi-component petroleum hydrocarbons from residual sources; Sadhana $\mathbf{3 9}$ (6) 1387-1408.

Weber W J J, McGinley P M and Katz L E 1991 Sorption phenomena in subsurface system concepts, models and effects on contaminant fate and transport; Water Resour. Res. 25 499-528.

Winograd I J and Robertson F N 1982 Deep oxygenated ground water: Anomaly or common occurrence?; Science 216(4551) 1227-1230. 